\title{
Eine andere Moderne im Paris der Dritten Republik. Die „Fontaines Wallace“ und Jules Coutans „Porteuse de pain“ als Avantgarde-Kunst
}

\author{
Hans KÖRNER
}

\begin{abstract}
Of the two studies that deal with works of the 'other modernity' of the French 19th century, the first deals with objects that, as multiply producible and stylistically eclectic objects, fell through the Modernist grid, although they correspond exactly to a definition of the avant-garde as formulated in the succession of Saint-Simon. The second asks whether the iconography of "modern life", in the sense of Charles Baudelaire's "Le peintre de la vie moderne", should not be added to the definition of modernity - against a limited formalist definition of modernity.
\end{abstract}

Keywords: Wallace, Coutan, Manet, Avant-Garde Definition, Modernity, French $19^{\text {th }}$ c. Sculpture, Fountain, Monument

In einer Zeit (der unseren), in der der Mainstream der Avantgarde Blockbuster-Ausstellungen garantiert, in der die allgemein akzeptierte Erzählung von der Moderne längst die Ausstattung der bürgerlichen Wohnzimmer und der Arztpraxen prägt, in einer Situation, in der das von Adorno der Avantgarde zugetraute kritische Potential zur erfolgreichen Ware im Kunstbetrieb verkommen ist, muss über historische Alternativen nachgedacht werden. War das ästhetische und gesellschaftskritische Potential der ,Bildhauer des modernen Lebens', wie ich Charles Baudelaires „Le peintre de la vie moderne“ variieren möchte, und die nicht deckungsgleich sind mit denen, die in den kunsthistorischen Handbüchern die moderne Bildhauerei vertreten, vielleicht doch innovativ und für einen erweiterten Begriff der Moderne wichtig? Von den beiden Studien, die im folgenden Bildwerke dieser , anderen Moderne' des 19. Jh. behandeln, thematisiert die erste Objekte, die als multipel produzierbare und stilistisch eklektizistische Objekte durch das Raster der Moderne fielen, obwohl sie einer Definition von Avantgarde, wie sie im französischen 19. Jh. formuliert wurde, exakt entsprechen; die zweite fragt, ob die Ikonographie des ,,modernen Lebens“ nicht doch - gegen die eingeschränkt formalistische Definition von Modernität - zu einer Definition von Moderne hinzukommen sollte.

\section{I.}

Kunst aus Paris für einen Engländer Trinkwasser für Paris von einem Engländer. Richard Wallace, seine Sammlung und seine Brunnen

Amélie Poulain befreit sich aus der provinziellen Enge ihres Elternhauses, flieht aus der Isolation, in die sie die überängstlichen Eltern wegen einer angeblichen Herzschwäche gesperrt hatten, flieht vor dem morbiden Kult, den der Vater nach dem Tod der Mutter zelebrierte: sie geht nach Paris. Dort beschließt sie, sich in das Leben anderer Menschen einzumischen: als hilfreicher Schutzengel und, wenn 


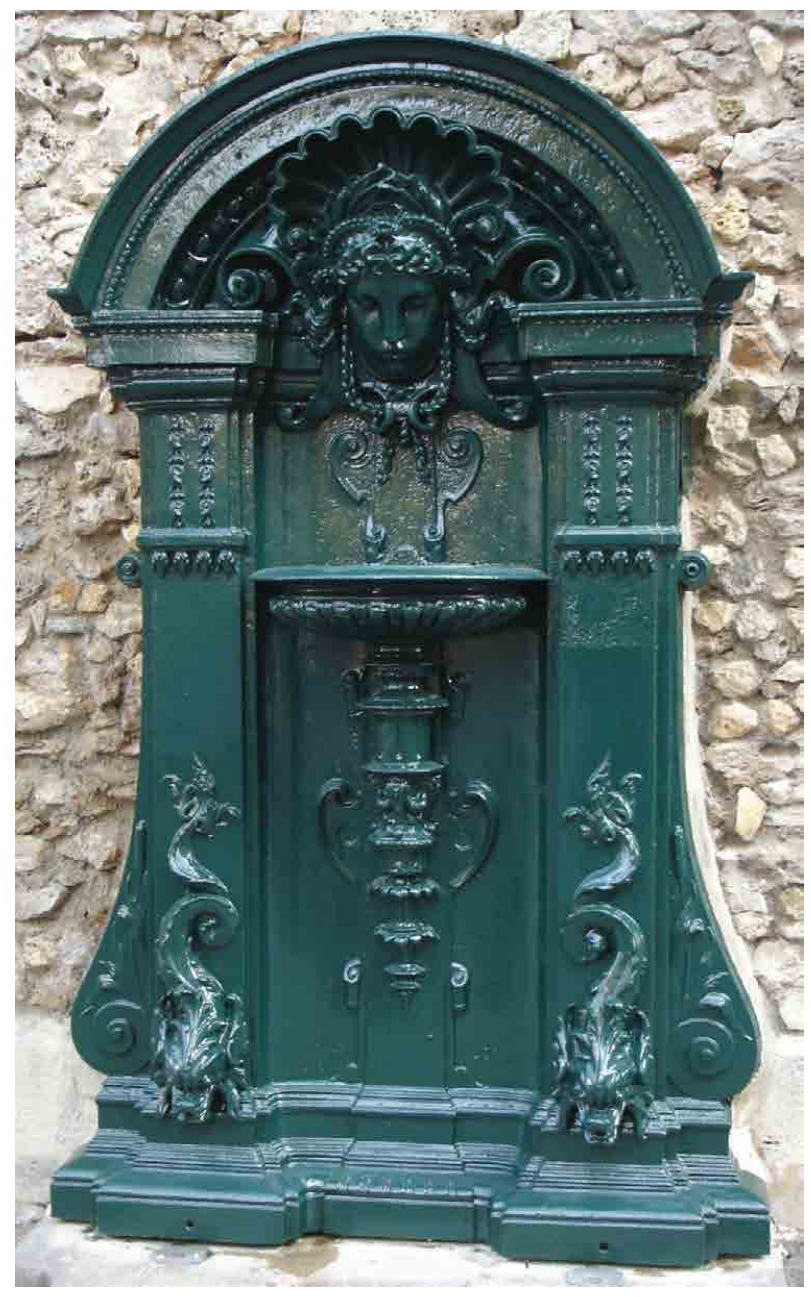

Abb. 1: Wallace, Richard-Lebourg, Charles-Auguste, Fontaine Wallace (Wandbrunnen), 1872 oder wenig später, Paris, rue Geoffroy Saint-Hilaire. Foto: Wikimedia Commons, Marie-Lan Nguyen.

nötig, als strafender Kobold. Sie mischt sich auch in das Leben der Concierge des Hauses ein, in dem sie eine Mietwohnung bezogen hat. Mme Wallace ist seit langen Jahren unglücklich, weil ihr Verlobter sie kurz vor der Hochzeit verlassen hat. Amélie tröstet sie; sie fälscht einen Brief des Treulosen, in dem er - vor seinem vorgeblichen plötzlichen Tod, der die bereits fest geplante Rückkehr verhindert habe - bereut und

\footnotetext{
Leider hat Wikipedia den Zusammenhang inzwischen auch notiert: https://fr.wikipedia.org/wiki/Fontaine_Wallace (16. 3. 2020).
}

seine Liebe beteuert. Es waren die Tränen der Concierge, die den Schutzengel / Kobold Amélie gerührt hatten. Sie habe nahe am Wasser gebaut, gesteht Madeleine Wallace Amélie. Schließlich trage sie den Namen der hl. Büßerin Magdalena, und zudem heiße sie Wallace. Vermutlich werden nur die französischen Kinobesucher diese Anspielung verstanden haben, konnten die Brücke gehen, die diese Fimszene aus dem 2001 in die Kinos gekommenen Film „Le fabuleux destin d'Amélie Poulain“ zwischen Tränen, Flüssigkeit im allgemeinen und Brunnen, die unter dem Namen Wallace-Brunnen bekannt sind, schlug. ${ }^{1}$

Von diesen Brunnen soll in diesem ersten Beitrag die Rede sein, sowie von Richard Wallace und von der Beziehung dieses Engländers zu Paris. Wandbrunnen gehen auf seine Stiftung zurück. (Abb. 1) Ein halbrunder Abschluss überfängt den Brunnen, in dessen Giebelfeld ein Maskaron, umrahmt von einer Muschel, eingelassen ist. Das Maskaron speit das Trinkwasser aus, das aus einem am Brunnen zur Verfügung gestellten Zinnbecher getrunken werden konnte. Von diesen Wandbrunnen wurden allerdings nur wenige produziert, und erhalten hat sich nur noch ein Exemplar in der Rue Geoffroy Saint-Hilaire. Sehr viel präsenter ist demgegenüber das sogenannte „Große Modell“, freistehende Brunnen, die zum Stadtbild von Paris so sehr gehören, dass ohne sie Paris nicht das wäre, was es ist. (Abb. 2, 3) Weitere Brunnentypen kamen später dazu, finanziert von der Stadt Paris und unabhängig von Richard Wallace, aber in Anlehnung an seine Brunnen: ein Wandbrunnen mit einem Satyrkopf, eine kleine freistehende Version und eine Variante des großen Modells, in der die Karyatiden durch Säulchen ersetzt sind; letztere sind bis auf zwei Exemplare verschwunden. ${ }^{2}$ Der vorliegende Beitrag beschränkt sich auf denjenigen Brunnentyp, der der prominenteste unter den Brunnentypen geblieben ist. Doch der Sprung von den Tränen der Madeleine Wallace zu den Wallace-Brunnen war wohl zu unvermittelt. Ich will deshalb neu ansetzen und zuerst vom Namensgeber dieser Brunnen reden, von Sir Richard Wallace, seinen Vorfahren und seiner Beziehung zu Paris.

2 https://fr.wikipedia.org/wiki/Fontaine_Wallace (30. 11. 2020). 


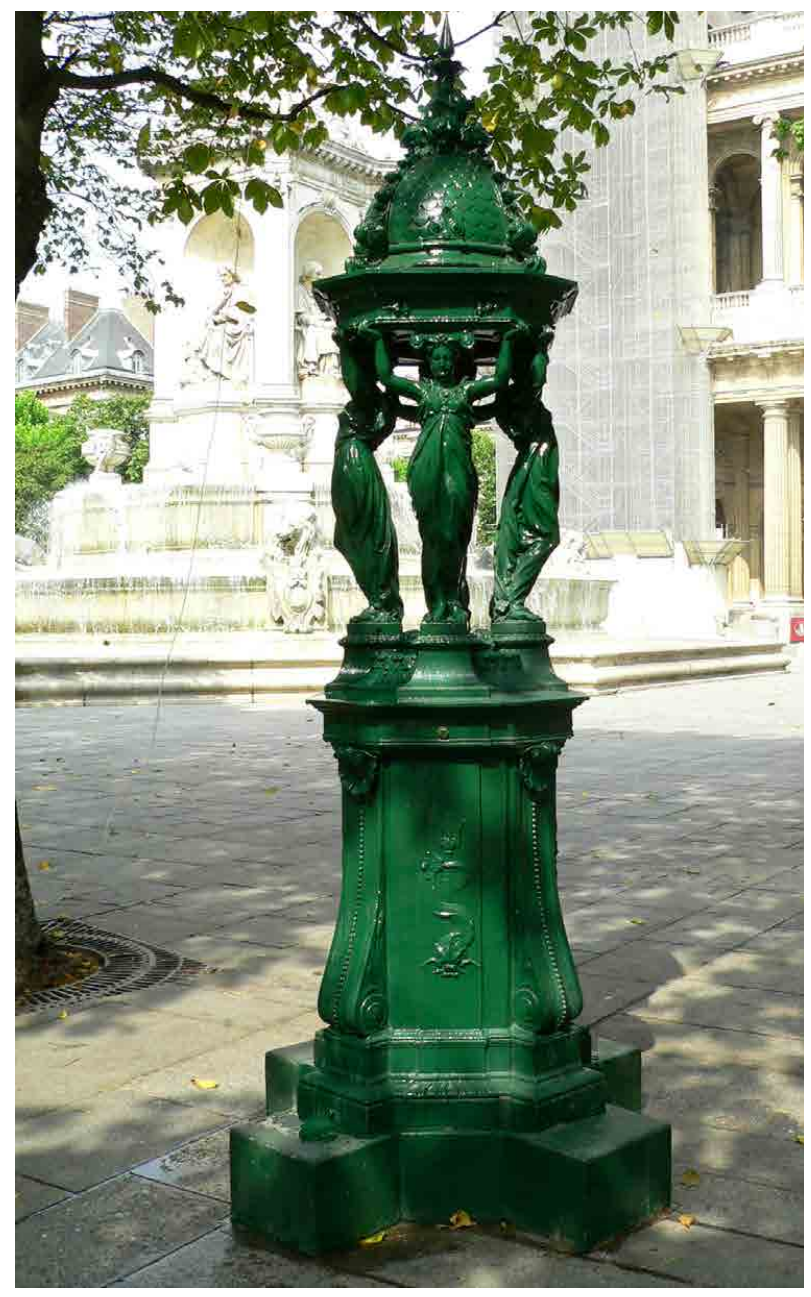

Abb. 2: Wallace, Richard-Lebourg, Charles-Auguste, Fontaine Wallace (Großes Modell), 1872 oder wenig später, Paris, Place Saint-Sulpice. Foto: Wikimedia Commons, Clio20.

\section{Die Wallace-Collection und der Philanthrop Richard Wallace}

Die Familie gehört zur gesellschaftlichen Spitze Englands. Earls of Hertford sind bereits im 12. Jh. nachweisbar; seit dem 16. Jh. steht ihnen die Herzogswürde zu: sie nennen sich jetzt Marquesses

\footnotetext{
3 https://en.wikipedia.org/wiki/Marquess_of_Hertford (21. 4. 2019). Zu den folgenden Ausführungen zur Familiengeschichte und zur Sammlungstätigkeit der Marquesses of Hertford und von Richard Wallace INGAMELLS, J: Die Wallace Collection London (= Museen der Welt), (1990 engl.).
}

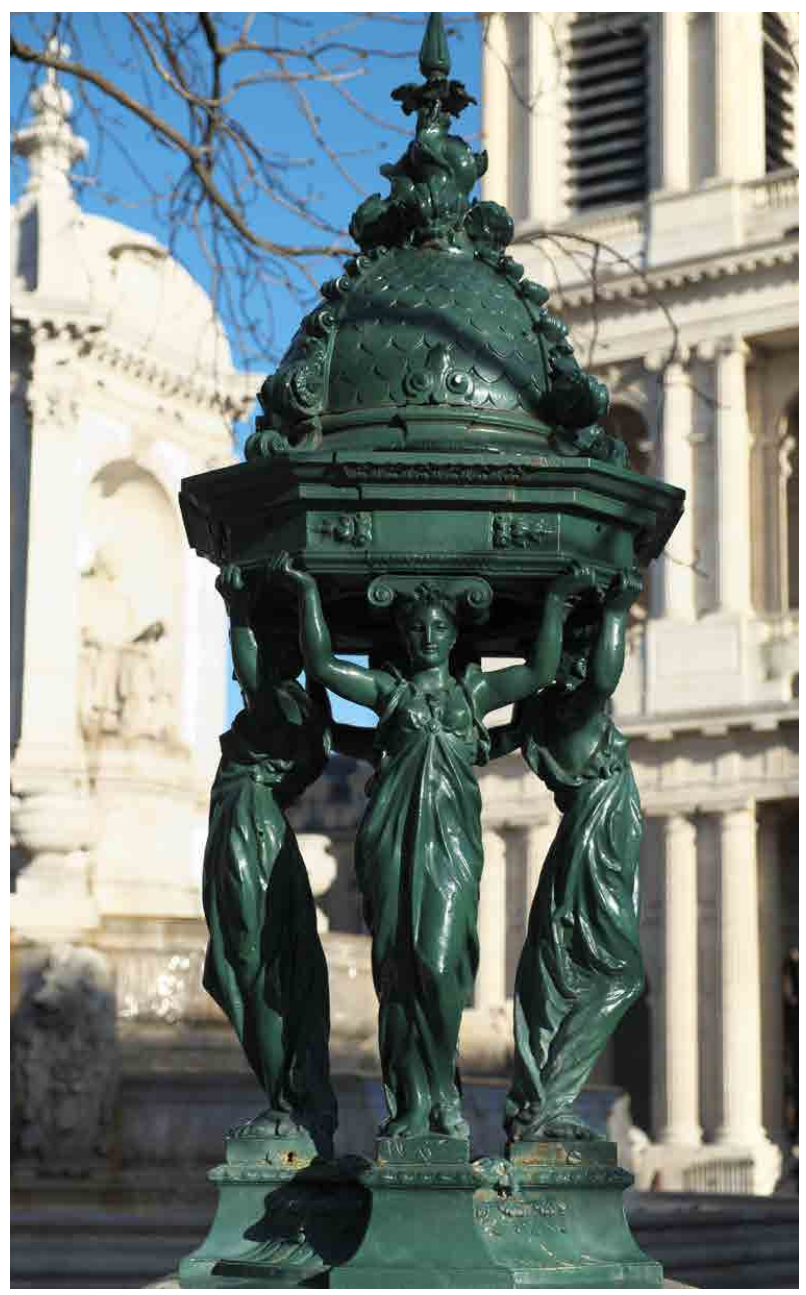

Abb. 3: Wallace, Richard-Lebourg, Charles-Auguste, Fontaine Wallace (Großes Modell), 1872 oder wenig später, Paris, Place Saint-Sulpice (Detail). Foto: Wikimedia Commons, Gfreihalter.

of Hertford. Dass eine Herzogsfamilie auch Kunstwerke in ihrem Besitz bringt, bedarf keiner längeren Ausführung. Zu Kunstsammlern im engeren Sinne wurden die Marquesses of Hertford erst im späteren 18. Jh. ${ }^{3}$ Francis, der dritte Marquess of Hertford fing damit im größeren Stil an. Mit dem Prinzen von Wales, den späteren König George IV., verband ihn

München 1990, S. 7 ff.; MONTEBIANCO, R.: Sir Richard Wallace. Cet illustre inconnu. Paris 2007, S. 8 ff.; HIGGOTT, S.: „The Most Fortunate Man of his Day. " Sir Richard Wallace: Connoisseur, Collector \& Philanthropist. London 2018, S. 17 ff. 
nicht nur eine langjährige Freundschaft, sondern auch die Leidenschaft für Ausschweifungen und für den Erwerb von Kunstwerken. Eine besondere Neigung hatte Francis, Marquess of Hertford, für die Malerei der Holländer des 17. Jhs., doch nicht zuletzt auf Anraten des Prinzen von Wales hin, blieb auch Frankreich im Blickfeld, französische Möbel insbesondere. ${ }^{4}$ Eher versehentlich griff er auch einmal nach Italien und erwarb etwa das Gemälde, in dem Perseus die angekettete Andromeda vor dem Drachen rettet. Es hing bis zum Ende des 19. Jhs. über der Badewanne von Richard Wallace, ehe sich die Einsicht einstellte, dass die Badezimmerdekoration ein echter Tizian ist. ${ }^{5}$

Francis' Sohn Richard, der vierte Marquess of Hertford war als Kunstsammler eine Ausnahmeerscheinung. Die Menge und Qualität der von ihm zusammengetragenen Werke war außerordentlich. Gleich seinem Vater sammelte er Holländer des 17. Jh., jetzt aber Meisterwerke wie Rembrandts „Bildnis seines Sohnes Titus“ oder den „Lachenden Offizier" von Frans Hals. Flämische und spanische Malerei sind mit einigen herausragenden Objekten vertreten. Genannt seien nur eine der berühmtesten Landschaften von Rubens, die „Landschaft mit dem Regenbogen" und das Bildnis einer unbekannten spanischen Frau von der Hand des Diego Velázquez. Weit in der Überzahl in der Sammlung von Richard of Hertford waren Werke der französischen Kunst. Die beiden großen Leinwände François Bouchers mit der mythologischen Interpretation von Sonnenauf- und Sonnenuntergang, Bilder, die Mme Pompadour für sich und für den König zur Erinnerung an ihre Liebe hatte malen lassen, brachte er 1855 in seinen Besitz. Eines der bedeutendsten Bildnisse der Pompadour besaß er. Außerdem eine veritable Ikone des verklingenden französischen Rokoko; Fragonards „Schaukel““. Schließlich neben dem Louvre, neben dem Prado und neben Berlin

\footnotetext{
4 INGAMELLS 1990 (wie Anm. 3), S. 9.

5 Ibidem, S. 35.

6 Ibidem, S. 9.

7 HIGGOT'T 2018 (wie Anm. 3), S. 43 ff.

8 Agnes Wallace selbst hatte den Namen Jackson nach der
}

eine der bedeutendsten Watteau-Sammlungen der Welt. Nicht zu vergessen: die prachtvollen Möbel des französischen 18. Jhs.

Die Dominanz französischer Kunst in der Sammlung des vierten Marquess of Hertford ist nicht zufällig. Statt, was ihm offen gestanden hätte, in England Karriere als Politiker zu machen, zog er es vor, in Paris zu leben; er residierte in dem kleinen Schlösschen Bagatelle im Bois de Boulogne. Ein standesgemäßes Stadtappartement in Paris an der Ecke der Rue Lafitte zum edlen Boulevard des Italiens besaß er auch. Hier und im Bois de Boulogne führte er ein zurückgezogenes Leben, verkehrte gleichwohl in den höchsten Kreisen - mit Kaiser Napoleon III. und Kaiserin Eugénie war er befreundet -, und er sammelte Kunst, französische Kunst des 18. Jhs. mit Vorzug. ${ }^{6}$ Er sammelte so viel, dass er Hilfe benötigte. Sein Sohn Richard war als Sekretär und als Kunstagent für den Vater tätig und kuratierte dessen Kunstsammlung. Zu einem herausragenden Kenner hatte er sich gebildet, ohne dessen Kompetenzen die Sammlung des Vaters nicht die geworden wäre, die sie schließlich geworden ist. ${ }^{7}$ Richard war der illegitime Sohn des Herzogs. Gezeugt hatte ihn der vierte Marquess of Hertford im Jahr 1818 in London. Die Mutter hieß Agnes Jackson und war eine gebürtige Wallace. 1842 nahm Richard Jackson aus ungeklärten Gründen den Mädchennamen seiner Mutter an. ${ }^{8}$ Aus Richard Jackson wurde Richard Wallace. 1870 verstarb der vierte Marquess of Hertford in Paris. Er war unverheiratet geblieben. Legitime Nachkommen hatte er nicht; so fiel Richard Wallace 1870 das gesamte Vermögen zu, einschließlich der Kunstsammlung. ${ }^{9}$

Nach dem Tod des Vaters sammelte Richard Wallace weiter: Er sammelte Holländer, Franzosen bevorzugt, u. a. m., und als er 1890 wie sein Vater in Bagatelle starb, hinterließ er eine der größten und bedeutendsten Privatsammlungen der Welt.

Trennung von ihrem Gatten Samuel Brickly angenommen. A General Guide to the Wallace Collection, London 1976, S. 20.

9 INGAMELLS 1990 (wie Anm. 3), S. 13; MONTEBIANCO 2007 (wie Anm. 3), S. 51; HIGGOTT 2018 (wie Anm. 3), S. 35, 108. 1838 hatte der vierte Marquess of Hertford noch seinen Bruder Henry als Erben eingesetzt, das aber 1850 zugunsten seines illegitimen Sohnes Richard geändert. General Guide 1976 (wie Anm. 8), S. 13. 
Geheiratet hatte er 1871 Julie Castelnau, eine Pariser Parfümverkäuferin. ${ }^{10}$ Nach seinem Tod im Jahr 1890 verbrachte seine Witwe die Sammlung nach England. Ihrer Großzügigkeit ist es verdankt, dass London seit 1900 die Wallace-Collection besitzt, ein Museum mit Kunst vom Mittelalter bis zum 19. Jh., mit Kunsthandwerk, Malerei und Skulptur, und eben: mit einer der weltweit großartigsten Sammlungen an französischer Kunst des 18. Jhs. ${ }^{11}$

Der Tod des Vaters und die Übernahme des Erbes fielen in eine bewegte Zeit. Der vierte Marquess of Hertford war am 24. August 1870 verstorben, neun Tage vor der Schlacht von Sedan. Napoleon III. war nach der verlorenen Schlacht gefangen genommen worden. In Paris wurde der Kaiser daraufhin für abgesetzt erklärt und die Dritte Republik ausgerufen. Wenig später standen die deutschen Truppen vor Paris. Vier Monate lang belagerten sie die Stadt - von September 1870 bis zur Kapitulation der Stadt Ende Januar 1871. Wallace blieb keineswegs unberührt vom Leid der Pariser, und er half. Zunächst seinen englischen Landsleuten: Er ließ sich zum Vorsitzenden des „British Charitable Fund“ wählen, der notleidende Briten in Paris unterstützte. ${ }^{12}$ Große Summen stiftete er für das französische Militär, u. a. für eine Militärambulanz; er linderte die Probleme der armen Bevölkerung angesichts der extremen Kälte in diesem Winter von 1870/71, half den Opfern der Bombardierungen, gab Geld für Armenspeisung und für diejenigen, die ihre Wohnung verlassen mussten. ${ }^{13}$ Insgesamt unterstützte er die Bevölkerung der belagerten Hauptstadt mit 2500000 Francs. Dank seiner Finanzierung konnte ein Ballon konstruiert werden, mit dem das eingeschlossene Paris über die Köpfe der Belagerer hinweg Kontakt mit der „Regierung der nationalen Verteidigung“ in Bordeaux aufneh-

\footnotetext{
${ }^{10}$ MONTEBIANCO 2007 (wie Anm. 3), S. 66; HIGGOT'T 2018 (wie Anm. 3), S. 62.

${ }^{11}$ HIGGOT'T 2018 (wie Anm. 3), S. 321 ff.

${ }^{12}$ Ibidem, S. 110 f.

${ }^{13}$ MONTEBIANCO 2007 (wie Anm. 3), S. 53 ff.; HIGGOTT 2018 (wie Anm. 3), S.111.
}

men konnte. In großen Lettern trug der Ballon den Namen Richard Wallace. ${ }^{14}$ Kurzum: Richard Wallace war ein Philanthrop, ein großer Wohltäter in einer für Paris sehr harten Zeit.

Paris kam auch nach der Kapitulaition nicht zur Ruhe. In der Frage, ob ein rascher Frieden mit Preussen anzustreben oder weiter Widerstand geleistet werden solle, hatte sich die von Adolphe Thiers geführte Regierung bereits von den die Pariser Politik dominierenden (linken) Republikanern entfernt. ${ }^{15}$ Aus Sorge wegen des revolutionären Potentials in der belagerten Stadt setzte sich die Regierung nach Versailles ab. Ihr Befehl vom 18. März, die Pariser Nationalgarde zu entwaffnen, bewirkte das Gegenteil. Die mit der Übernahme der Kanonen beauftragten Soldaten der Regierung verbrüderten sich mit der Nationalgarde und schlossen sich ihrem Aufstand gegen die eingesetzte „Regierung der nationalen Verteidigung“ an. In Paris begannen die Tage der Kommune, eine Zeit der Gewalt, des Vandalismus aber auch der Einführung radikaler demokratischer Praktiken, sozialer Reformen, der Gleichberechtigung der Frauen. Richard Wallace blieb während der Zeit der Kommune in Paris und war in Sorge um die Sicherheit seiner Kunstsammlung. Nicht zu Unrecht, wenn man sich klarmacht, dass die Kommunarden nahe daran gewesen waren, den Louvre mit allen seinen Schätzen niederzubrennen. Doch weder seine Person noch seine Sammlung wurden bedroht. Ihn schützte gewiss die allgemeine Verehrung, die die Pariser dem reichen Engländer für seine massive finanzielle Hilfe während der Zeit der Belagerung entgegenbrachten. Erst nach Niederschlagung der Kommune konnte er nach London zur Regelung seiner Angelegenheiten reisen. Im Hochsommer 1871 war Richard Wallace wieder in Paris. ${ }^{16}$

${ }^{15}$ Das folgende wiederholt eine Passage aus KÖRNER; H.: Die Mauer. Zur Materialität der Erinnerung im französischen Denkmal des 19. und frühen 20. Jahrhunderts. In: Materielle Mediationen im französisch-deutschen Dialog. Eds. BORSÓ, V. HÜLSEN-ESCH, A. VON (= Materialität und Produktion 2, Ed. HÜLSEN-ESCH, A. VON u. a.). Berlin - Boston 2019, S. 135-164, hier S. 143.

${ }^{16}$ HIGGOTT 2018 (wie Anm. 3), S. 115 ff.

${ }^{14}$ HIGGOTT 2018 (wie Anm. 3), S.112. 


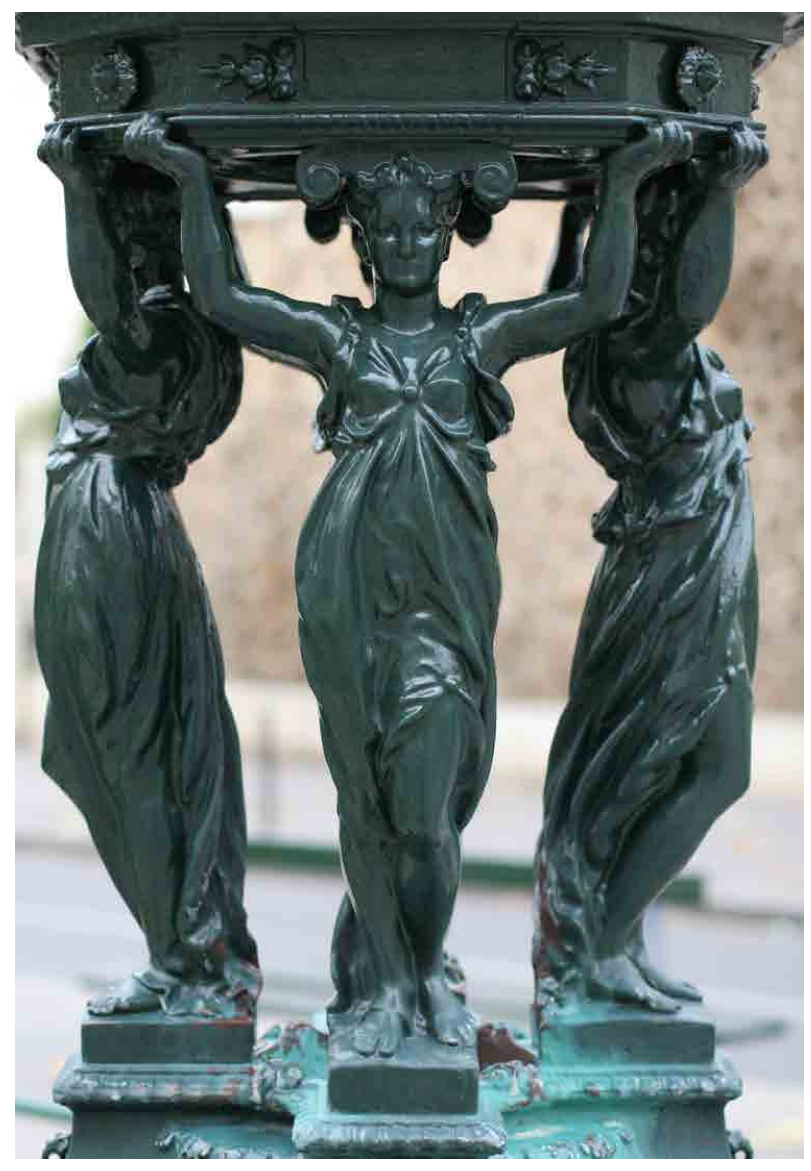

Abb. 4: Wallace, Richard-Lebourg, Charles-Auguste, Fontaine Wallace (Großes Modell) Paris Place, Moussa-et-Odette-Abadie (Detail), 1872 oder wenig später. Foto: Wikimedia Commons, Coyau.

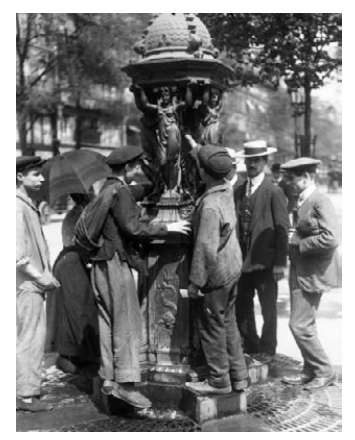

Abb. 5: Wallace, Richard-Lebourg, Charles-Auguste, Fontaine Wallace (Großes Modell), Fotografie 1911. Foto: Archiv des Autors.

${ }^{17}$ Ibidem, S. $123 \mathrm{f}$.

${ }^{18}$ Die Pariser Stadtverwaltung beteiligte sich mit jeweils 1000 Fr. an den „Großen Modellen“ und mit 450 Fr. an den Wandbrunnen. https://fr.wikipedia.org/wiki/Fontaine_Wallace (12. 5. 2019).

\section{Die Brunnen des Richard Wallace}

Die Zerstörungen während der Belagerung und unter der Kommune hatten nicht zuletzt zu Problemen bei der Trinkwasserversorgung geführt. ${ }^{17}$ Erneut betätigte sich der Engländer Richard Wallace in seiner Wahlheimat Paris als Wohltäter. Er stiftete zahlreiche Brunnen, die über Paris verteilt, die Trinkwasserversorgung sicherten. ${ }^{18}$ Dafür griff er nicht nur tief in seinen Geldbeutel, sondern war selbst kreativ dabei. Er lieferte die Entwürfe für einen Wandbrunnen und für das sehr viel häufiger produzierte sogenannte „Große Modell“. ${ }^{19}$ (Abb. 4, 5) Die Brunnen dieses sogen. „Großen Modells“ bauen jeweils auf einem viereckigen Sockel auf, den Voluten an den Kanten zum Achteck ergänzen. Darüber Frauenfiguren, Karyatiden, die mit dem Kopf ein jonisierenden Kapitell und mit beiden Händen ein Gebälk stützen, über dem sich eine kleine Kuppel wölbt. Diese Kuppel birgt das Trinkwasser, das im Inneren des Tempelchens fließt. Die Karyatiden sind in lange Gewänder gekleidet, die sich über den Brüsten straffen. Sehr ähnlich sind jeweils die vier Stützfiguren, doch nicht identisch. Die Gewänder variieren leicht und abwechselnd ist das linke oder das rechte Bein vorgestellt. Material ist Gusseisen, gemäß den Vorgaben von Richard Wallace, dass ein widerstandsfähiges Material zu verwenden sei, das multipel und preiswert produziert werden könne. ${ }^{20}$ Richard Wallace gab, wie erwähnt, den Entwurf vor; für die Ausführung engagierte er einen professionellen Künstler. Der Bildhauer Charles-Auguste Lebourg hatte bereits für die Familie gearbeitet und unter anderem die Büste des vierten Marquess von Hertford geschaffen. Ihn beauftragte Richard Wallace mit der Umsetzung seines Konzeptes. ${ }^{21}$

Dass die vier Frauen, die den Wasserbehälter hochstemmen, nicht Frauen der Dritten Republik sind, ist offensichtlich. Sie haben ihre Verwandten in der französischen Renaissance des 16. Jh., ein kunsthistorischer Rückgriff, der bei dem großen

${ }^{19}$ Einen guten Überblick gibt: https:// fr.wikipedia.org/wiki/ Fontaine_Wallace (12. 5. 2019).

${ }^{20}$ Ibidem.

${ }^{21}$ HIGGOT'T 2018 (wie Anm. 3), S. 124. 
Connoisseur und Sammler Richard Wallace nicht überrascht. Lässt sich die kunsthistorische Spur genauer zurückverfolgen? Wikipedia nennt die „Fontaine des Innocents“ als Vorbild. ${ }^{22}$ Die Bezüge sind zu lose.

Ernster zu nehmen ist das von Roland Montebianco in die Diskussion gebrachte Vorbild: Die „Drei Grazien“ des Germain Pilon. ${ }^{23}$ (Abb. 6) Pilons „Grazien“ bilden den figürlichen Schmuck des Grabmals, das das Herz König Heinrichs II. barg. Das Herzmonument des 1559 infolge der Verletzung bei einem Turnier umgekommenen Königs stand ursprünglich in der Église des Célestins in Paris. Über die komplexe Entstehungsgeschichte dieses Monuments nur soviel: Der Entwurf geht wohl auf Primaticcio zurück, der die Aufgaben für dieses Monument auf mehrere Künstler verteilte, und darunter die „Grazien“ an Germain Pilon, die laut Zahlungsbelegen zwischen 1560 und 1563 entstanden sein dürften. ${ }^{24}$ Vergleichbar den Trägerfiguren der Wallace-Brunnen sind die Körperhaltungen von Pilons Grazien, und ähnlich verhüllt und enthüllt die Bekleidung die Körper der Frauenfiguren. Vor allem ähnelt die kleine Kuppel, das heißt: der Wasserbehälter, der Herzurne. Es ist allerdings nicht mehr die ursprüngliche Urne. Dass die Große Revolution das königliche Herz nicht verschonte, überrascht nicht. Die Urne wurde eingeschmolzen. Das gesamte Monument war kurz davor, zerstört $\mathrm{zu}$ werden, doch Alexandre Lenoir rettete es wie viele andere Objekte, abzüglich der Herzurne in sein Musée des Monuments français. Von da kann es 1816 in den Louvre; die zerstörte Urne wurde durch eine Nachbildung ersetzt. ${ }^{25}$

Die Abhängigkeit von Germaine Pilons Grazien kann auch eine vermittelte gewesen sein. Im 19. Jh. waren Bronzestatuetten, gelegentlich versilbert oder vergoldet, nach Pilons Werk (hergestellt und vermarktet von der Gießerei Barbedienne) weit verbreitet. Erwartungsgemäß trugen diese Reduktionen keine Herzurne mehr; sie blieben entweder

\footnotetext{
${ }^{22}$ https://fr.wikipedia.org/wiki/Fontaine_Wallace (12. 5. 2019).

${ }^{23}$ MONTEBIANCO 2007 (wie Anm. 3), S. 96.

${ }^{24}$ Dazu TERRASSE, CH.: Germain Pilon. Biographie critique (...) (= Les grands artistes. Leur vie, leur oeuvre). Paris 1930, S.
}

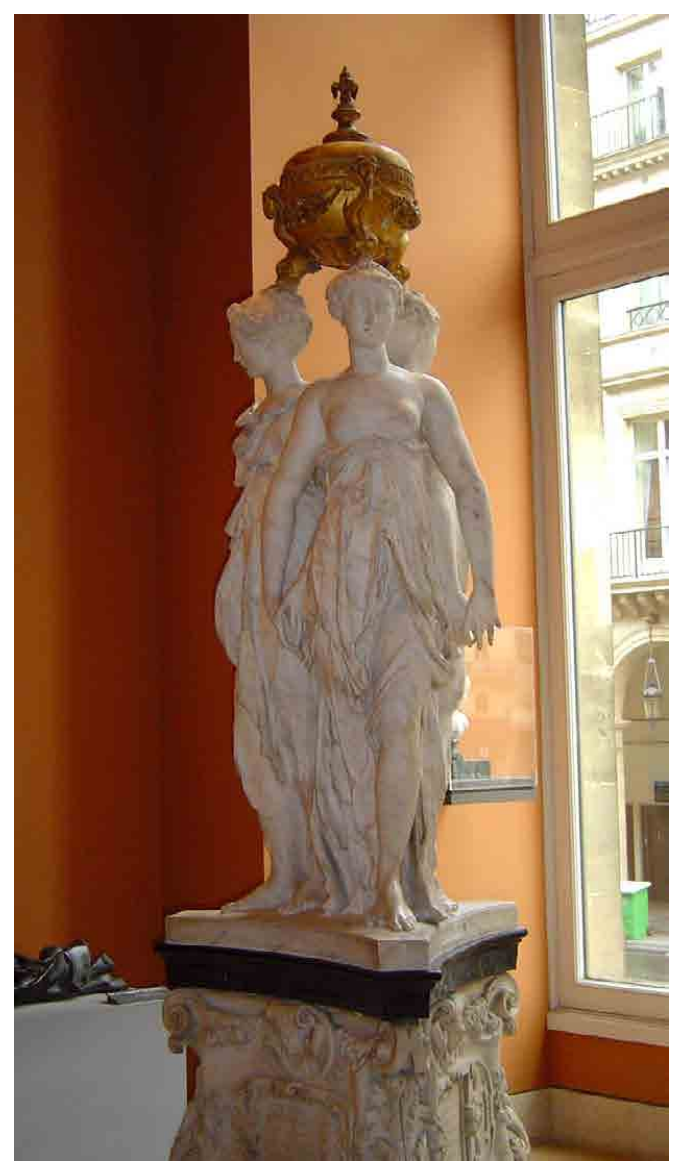

Abb. 6: Pilon Germain, Grazien vom Grabmal für das Herz. Heinrichs II., 1561-62, Paris, Musée du Louvre. Foto: Wikimedia Commons, Miniwark.

freigestellt oder waren verbunden mit Obstschalen, Gläsern, einer Uhr u. a. Das Grabdenkmal war in solchen Objekten zum Gebrauchsgegenstand, allerdings zu einem luxuriösen Gebrauchsgegenstand geworden. Auch als Brunnenfigur war Pilons Graziengruppe adaptiert worden. Das Rathaus von Saint-Denis wurde 1846 grundsteingelegt, war aber erst 1860 eingeweiht worden. Im Innenhof des Rathauses erhebt sich ein gusseiserner Brunnen mit

20 ff.; GAEHTGENS, TH. W.: Zum frühen und reifen Werk des Germain Pilon. Stilkritische Studien zur französischen Skulptur um die Mitte des 16. Jahrhunderts. Bonn 1967, S. 28 ff.

25 TERRASSE 1930 (wie Anm. 24), S. 36; GAEHTGENS 1967 (wie Anm. 24), S. 28. 


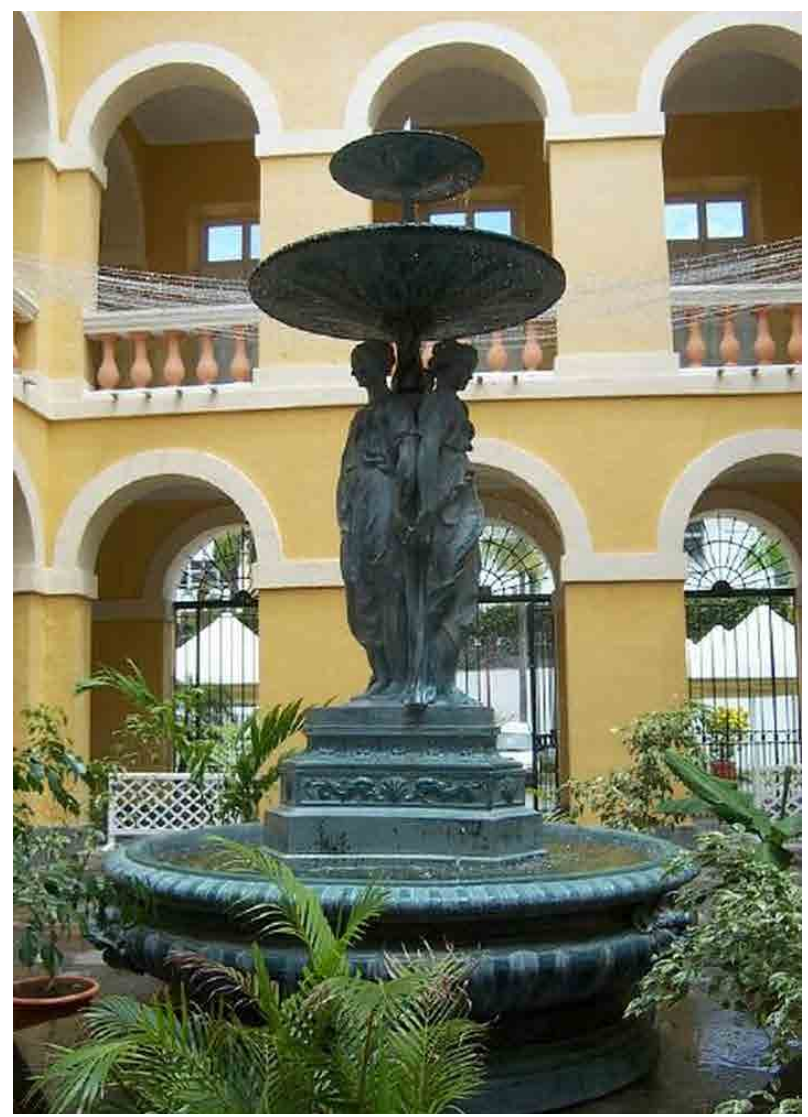

Abb. 7: Ducel, Jean-Jacques (Gießerei), Brunnen, Saint-Denis, Hôtel de Ville, Innenhof, 1860er Jahre. Foto: https:// wmw.saintdenis.re/Lancien-Hotel-de-ville.html.

der Pilonsches Gruppe unter zwei Brunnenschalen. ${ }^{26}$ (Abb. 7) Bestimmt hatte der Stifter, Bürgermeister Gustave Manès, den Brunnen für die Aufstellung vor der ehemaligen Abteikirche von Saint-Denis. Weil unter den dreien v. a. eine besonders freizügig bekleidete Renaissancegrazie an diesem Ort als anstößig erachtet wurde, verbrachte man den Brunnen an seinen heutigen Platz. ${ }^{27}$

\footnotetext{
${ }^{26}$ http://www.mi-aime-a-ou.com/photo_saint-denis.php?id_ img $=256$ (7. 5. 2019).

${ }^{27}$ https://www.saintdenis.re/L-Ancien-Hotel-de-Ville.html (7. 5. 2019).

${ }^{28}$ https://de.wikipedia.org/wiki/Erechtheion (7. 5. 2019).
}

Nun stützen die Grazien Pilons die Herzurne eher beiläufig. Die Grazien der Wallace-Brunnen stellen sich demgegenüber als Karyatiden aktiv in den Dienst des Brunnens. Man wird also weitere kunsthistorische Quellen heranziehen müssen. Inspiriert dürften Wallace die Koren des Erechtheions auf der Athener Akropolis haben, Karyatiden mit dem Kalathos auf dem Kopf. (Abb. 8) Sie mussten ihm bekannt sein, nichts zuletzt wegen der einen originalen Kore aus Athen, die 1811 ins British Museum verbracht worden war, ${ }^{28}$ und sicher auch wegen der Wiederholung der Erechtheion-Vorhalle, mit der Rossi um 1820 die Sakristei von St. Pancras in London geziert hatten. Eingeflossen in seine Brunnenkonzeption sind daneben gewiss auch die Karyatiden Jean Goujons unter der „Tribune des Musiciens“ im Karyatidensaal des Louvre. (Abb. 9) Doch die Brunnenfiguren des Richard Wallace betonen die Stützfunktion zusätzlich durch die nach oben gereckten Arme, die das Gebälk stemmen.

Ein weiterer Vorschlag hinsichtlich der kunsthistorischen Abkünftigkeit der Karyatiden der Wallace-Brunnen sei in die Diskussion eingebracht: Vier Frauengestalten, die ebenfalls Germain Pilon zugeschrieben worden waren, heute aber entweder als Werke eines Nachfolgers Pilons, des Architekten Le Mercier, Jean Goujons und neuerdings als Arbeiten Philippe Buysters gelten, ${ }^{29}$ trugen bis zur Revolution den Schrein der Pariser Lokalheiligen Genoveva in der Kirche Ste Geneviève. ${ }^{30}$ (Abb. 10) Die Revolution zerstörte den Schrein. Auch hier blieben nur die Stützfiguren, die schließlich ebenfalls im Louvre landeten. In Ermangelung des ursprünglichen Zusammenhangs stellte man sie auf einen Sockel, der eine Kopie des Sockels des Herzmonuments für Henri II ist. Anders als Pilons Grazien waren sie als Trägerfiguren aktiv - von den heute abgebrochenen Armen stützte jeweils einer den Heiligenschrein, der andere hielt eine Fackel

\footnotetext{
${ }^{29}$ https://www.latribunedelart.com/philippe-de-buyster-nouvelles-interrogations-nouvelles-attributions (13. 5. 2019).

${ }^{30}$ BABELON, J.: Germain Pilon (= L'artfrançais). Ed. WILDENSTEIN G. Paris 1927, S. 19, 70. Babelon schrieb Pilon die Tugenden zu.
} 


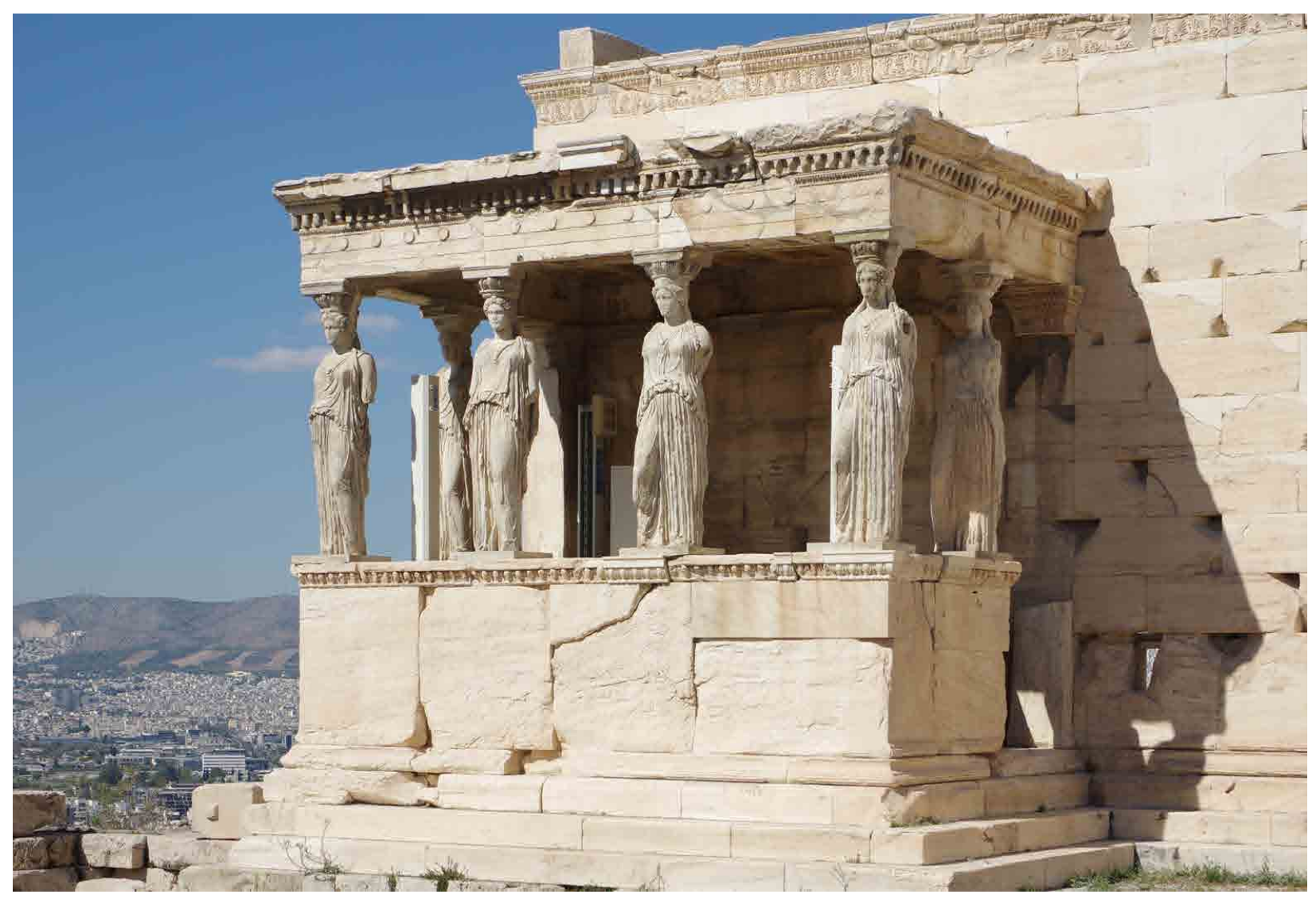

Abb. 8: Athen, Erechtheion, Vorhalle (Koren), 420-406 v. Chr. Foto: Wikimedia Commons, Berthold Werner.

hoch. Das bringt sie den Karyatiden des Richard Wallace ein Stück näher noch.

Richard Wallace fühlte sich nicht einem einzigen kunsthistorischen Vorbild verpflichtet; er schöpfte aus dem Fundus der Kunstgeschichte und führte diverse Anregungen zusammen. Eklektizismus nannte und nennt man diese Weise der Produktion von Kunst auf dem Weg über die Aneignung unterschiedlicher Vorbilder, und dieser Begriff des Eklektizismus wurde in der Moderne als abwertender Begriff eingesetzt. Die stereotypen Klassifizierungen und das Werteprofil der inzwischen längst selbst historisch gewordenen Moderne gehören auf den Prüfstand. Eine solche Prüfung könnte ergeben, zumindest läuft auf diese These der vorliegende Beitrag hinaus, dass die eklektizistischen Brunnen des Richard Wallace zur Moderne gehören, dass sie Avantgarde sind.

\section{Eklektizismus und Moderne}

Richard Wallace brachte Kunst in eklektizistischer Bündelung auf die Straße. Fraglos ist das eine Weise der Trivialisierung politisch, sakral und ästhetisch hoch aufgeladener Werke. Die Karyatiden des Erechtheions, das Herzmonument für Henri II., Jean Goujons Stützfiguren in der „Salle des Caryatides“ des Louvre, die Theologischen Tugenden vom Schrein der hl. Genoveva waren zur Straßenkunst gemacht worden. Das kulturell / künstlerisch Hohe wurden ins Niedrige gezogen. Symptomatisch dafür ist sicher die Transformation der Herzurne in einen Behälter, aus dem Trinkwasser fließt. Die Transformation hoher Form für eine alltägliche Bedürfnisbefriedigung, ist, wie wiederholt sei, eine Weise der Trivialisierung. Ist dies nicht eine Weise der Demokratisierung von Kunst? Ist es nicht ein pro- 


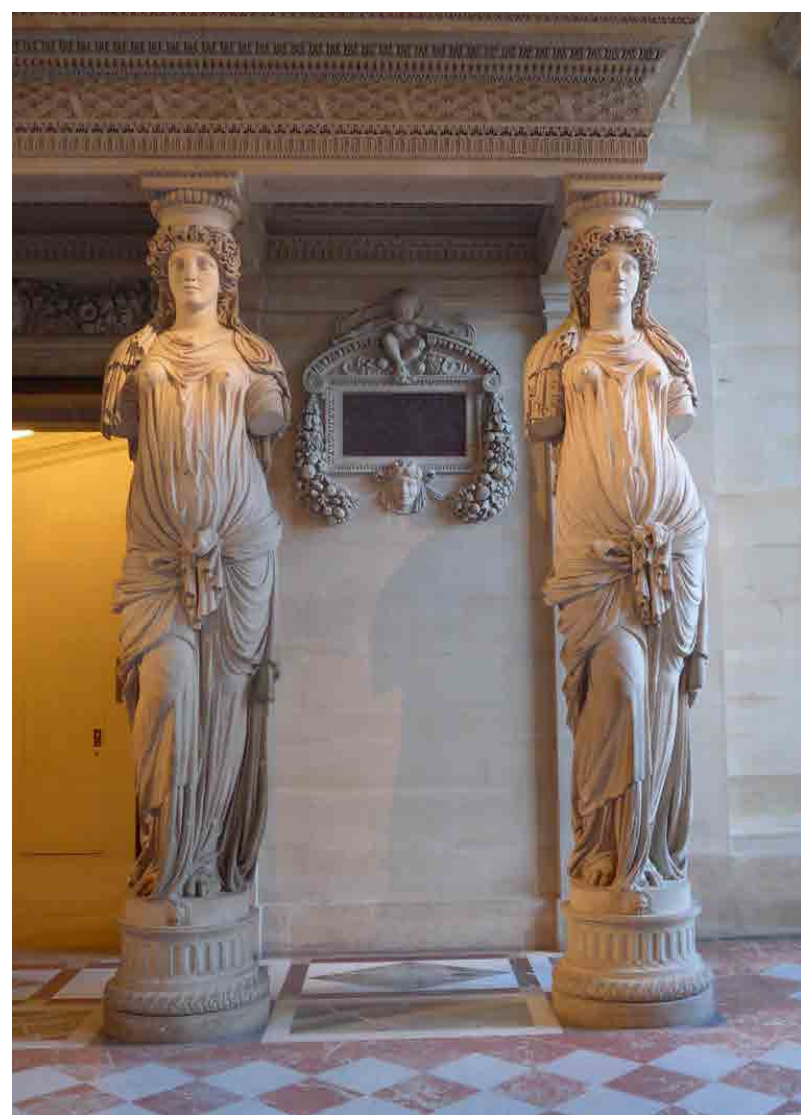

Abb. 9: Goujon, Jean, Tribune des Musiciens, Paris, Musée du Louvre (Salle des Caryatides), um 1550. Foto: Wikimedia Commons, Roi Roiability.

gressives Konzept von Kunst im öffentlichen Raum? Die heikle Frage der Bewertung solcher Objekte soll vorerst noch zurückgestellt werden. Zunächst ist der Kontext genauer in den Blick zu nehmen.

Das „Große Modell“ ist auch der Versuch, eine Lösung für eine Problematik zu finden, die spätestens mit der Ersten Weltausstellung 1851 in London

\footnotetext{
${ }^{31}$ BUDDENSIEG, T.: Das Alte bewahren, das Neue verwirklichen. Zur Fortschrittsproblematik im 19. Jahrhundert. In: Die nützlichen Künste. Gestaltende Technik und Bildende Kunst seit der Industriellen Revolution, Katalog der Ausstellung, Berlin, Messegelände am Funkturm 1981. Eds. BUDDENSIEG, T. - ROGGE, H. Berlin 1981, S. 47-66, hier S. 62. ,The common and the useful predominate far above fine and high art." Zit. nach BUDDENSIEG 1981 (wie Anm. 31), S. 62.
}

diskutiert wurde. In der Ausgabe vom 24. Mai 1851 kommentierten die „Illustrated London News“ das Verhältnis von angewandter und hoher Kunst und sprachen sich ganz im Sinne der Politik der Weltausstellungsmacher für erstere und gegen letztere aus. Die große Historienmalerei und die schönen Skulpturengruppen könnten das Volk nicht begeistern und sollten deshalb auch nicht gefördert werden. „Das Alltägliche und das Nützliche überragen weit die schöne und hohe Kunst. ${ }^{\text {“31 }}$ Die Wallace-Brunnen sind ein Versöhnungsangebot. Hohe und schöne Kunst, und dafür stehen nun einmal antikische Karyatiden, dafür stehen die vorbildhaften Künstler Germain Pilon und Jean Goujon, hat sich in den Dienst des Nützlichen, mehr noch: des für das Gemeinwohl Notwendigen gestellt. Sie konnte dies tun, weil die hohe und schöne Kunst sich auf das moderne Material Gusseisen $^{32}$ - und auf industrielle Massenfabrikation eingelassen hat. So konnte das Hohe zum Allgemeingut und das Schöne zum Nützlichen werden. Und wer will bestreiten, dass die Versöhnung nicht gelungen ist. Die Wallace-Brunnen haben das alltägliche Paris schöner gemacht und sie tun es weiterhin.

Diese Antwort des in Paris lebenden Engländers war eine französische Antwort auf eine englische Herausforderung. Schon kurz nach der Weltausstellung 1851 in London sah man sich in Frankreich verpflichtet, das dank Industrialisierung massentauglich gemachte Nützliche mit dem Schönen zu verbinden. Anders als die Londoner Weltausstellung sollte auf der Weltausstellung 1855 in Paris neben einer Industrieausstellung auch eine Kunstausstellung zu sehen sein, denn, wie Kaiser Napoleons III. in Vorbereitung dieser Ausstellung von 1855 dekretierte: „(D)ie Vervollkommnungen der Industrie sind eng gebunden an die der Schönen Künste. “33 Frankreich, so dann Comte de Laborde in einem Text von 1856 über die „,Vereinigung der Künste mit der Industrie“,

${ }^{32}$ Die vorindustrielle Gusseisentechnik ist selbstverständlich sehr viel älter. Dazu: WALTON, CH. W. (bearbeitet v. PATTERSON, W.): Gusseisen-Handbuch, (1957 / 1962, 2. Aufl., engl.). Düsseldorf 1963, S. 1 ff.

${ }^{33}$ MAAG, G.: Kunst und Industrie im Zeitalter der ersten Weltausstellungen. Synchrone Analyse einer Epochenschwelle. Konstanz 1982, S. 159. „les perfectionnements de l'industrie sont étroitement liés à ceux des beaux-arts“. Zit. nach ibidem, S. 159. 


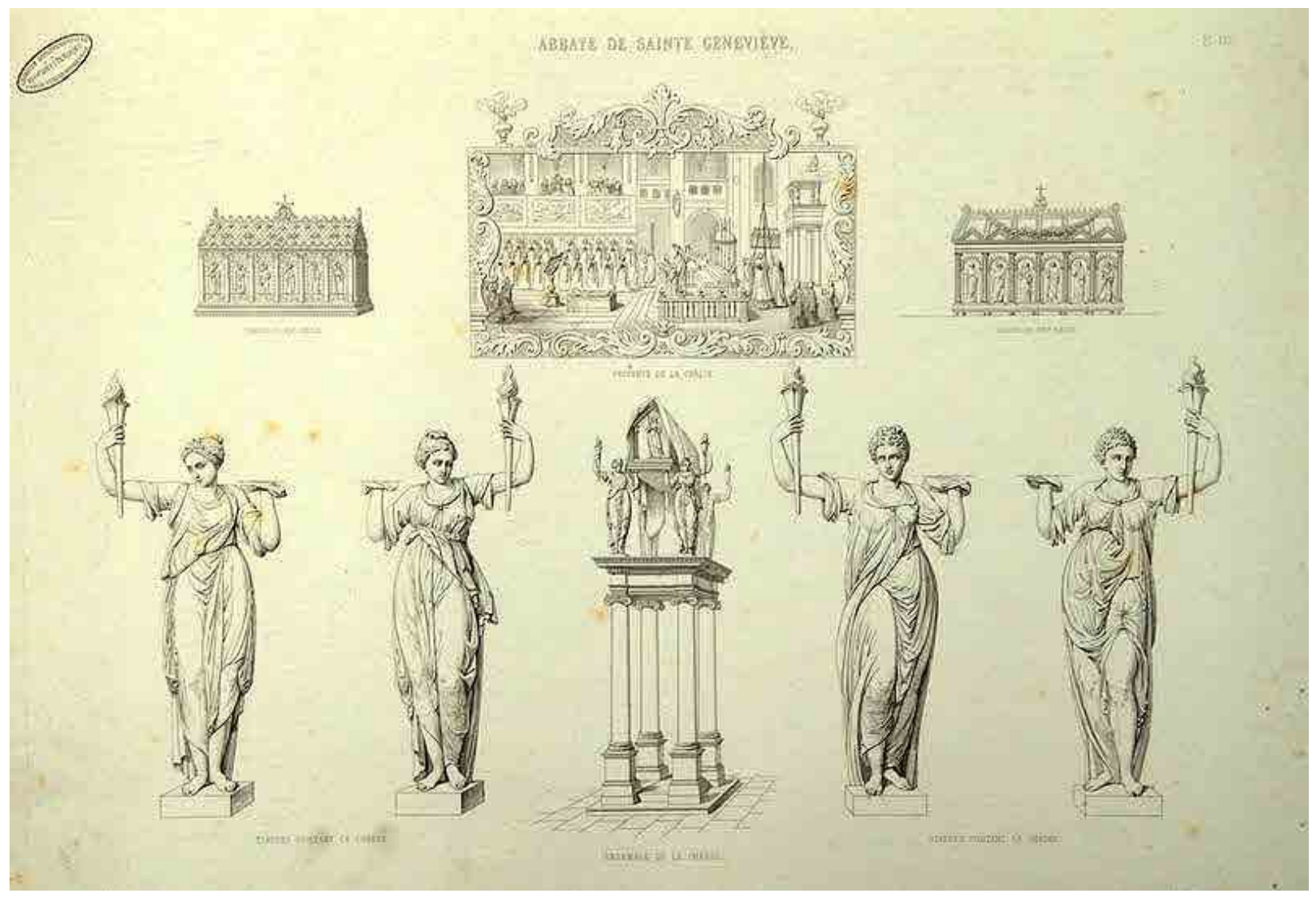

Abb. 10: Ehem. Paris, Ste. Geneviève, Schrein der hl. Genoveva mit den vier theologischen Tugenden als Stützfiguren, 1. Viertel 17. Jh. (Schrein zerstört 1792). Foto: http:/ / schola-sainte-cecile.com/2015/01/03/les-processions-des-reliques-de-sainte-genevieve/.

sei vorbildlich in Fragen des guten Geschmacks. Es sei die „Beharrlichkeit im Studium der Kunst“, die Frankreich auszeichne, und die dafür sorge, dass Frankreich sich wirtschaftlich in der Konkurrenz mit England behaupten könne. ${ }^{34}$

In anderer Hinsicht noch stehen die Brunnen des Engländers Wallace mit England in Beziehung und grenzen sich davon ab. Die Idee, das Netz der Versorgung der Bevölkerung mit Trinkwasser mittels vieler Brunnenanlagen in der Stadt so engmaschig wie möglich zu machen, war in England geboren worden. Die Philanthropen Samuel Gurney und

\footnotetext{
${ }^{34}$ Ibidem, S. 157. „De l'union des arts et de l’industrie“. „étude persévérante de l'art". Zit. nach ibidem, S. 157.

35 https://en.wikipedia.org/wiki/Metropolitan_Drinking_
}

Edward Thomas Wakefield hatten die „Metropolitan Free Drinking Fountain Association" gegründet, die sich das Ziel setzte, Brunnen in London zu bauen, Brunnen mit einer Filteranlage, die die Reinheit des Wassers garantierte. Den ersten Brunnen stiftete Samuel Gurney 1859 selbst. ${ }^{35}$ (Abb. 11) Ein Wandbrunnen, eingefasst von einem an der romanischen Architektur orientierten Rundbogen über zwei Säulen aus rotem Marmor. Der Erfolg war immens und bestätigte rückwirkend, wie notwendig Samuel Gurneys Initiative gewesen war. Ca. 7000 Menschen tranken pro Tag an diesem Brunnen ${ }^{36}$ und kamen

Fountain_and_Cattle_Trough_Association (25.4. 2019).

${ }^{36}$ https://www.historic-uk.com/HistoryMagazine/DestinationsUK/Londons-First-Drinking-Fountain/ (25. 4. 2019). 


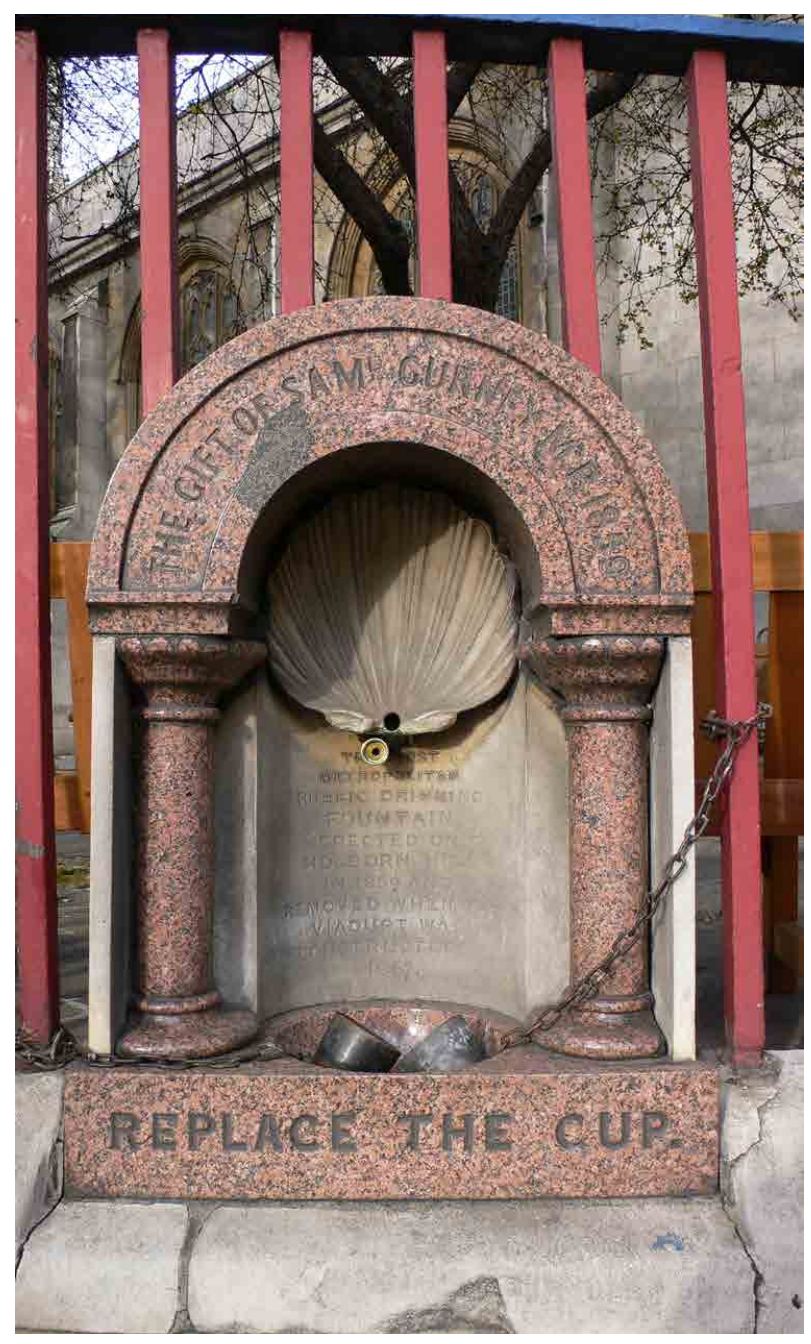

Abb. 11: Brunnen der „Metropolitan Free Drinking Fountain Association", 1859, London, Snow Hill. Foto: Wikimedia Commons, Justinc.

wohl auch der in die Basis eingemeisselten Aufforderung „Replace the Cup“ nach. (Anmerkung: Die an den Pariser Wallace-Brunnen bereitgestellten Zinnschalen wurden regelmäßig gestohlen.) Engländer sind Tierliebhaber. Deshalb sorgte man später dafür, dass auch Hunde, Katzen und Pferde ihren Durst stillen konnten. Es wurden allenthalben Viehtröge, „Cattle Troughs“, aufgestellt. Die „Metropolitan Free Drinking Fountain Association“ änderte darauf-

\footnotetext{
${ }^{37}$ https://en.wikipedia.org/wiki/Metropolitan_Drinking_ Fountain_and_Cattle_Trough_Association (25.4.2019).
}

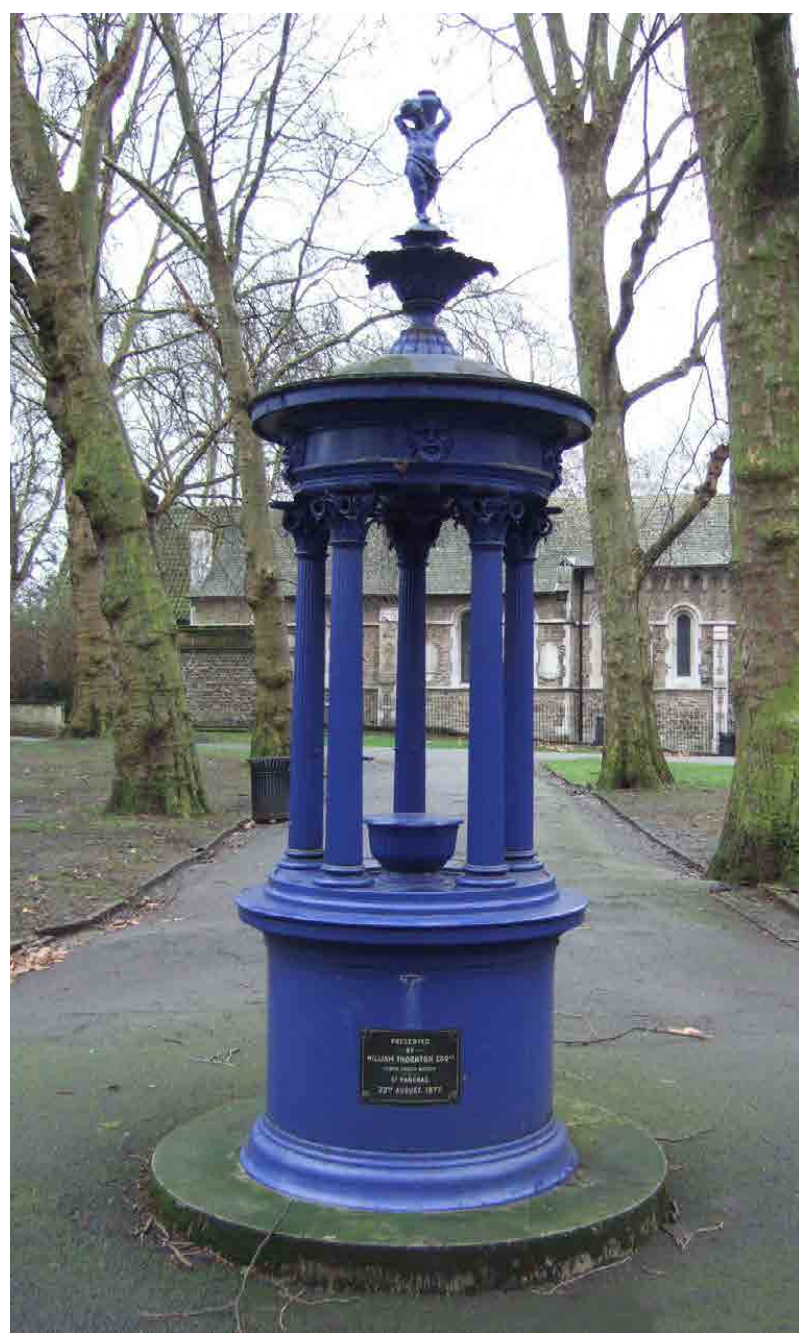

Abb. 12: Brunnen der „Metropolitan Drinking Fountain and Cattle Trough Association", 1877, London, St. Pancras, Old Church. Foto: http:/ / www.mdfcta.co.uk/ details-f/f069.html.

hin 1867 ihren Namen in „Metropolitan Drinking Fountain and Cattle Trough Association" ${ }^{37}$

Allein in den nächsten sechs Jahren nach Errichtung des ersten Brunnens nahe der St. Sepulchre's Church wurden von der „Metropolitan Free Drinking Fountain Association" in London 85 weitere Free Drinking Fountains errichtet, ${ }^{38}$ und viele weitere kamen im Verlauf des 19. und 20. Jhs. hinzu. Es gibt Wandbrunnen und freistehende Brunnen. Breit

\section{${ }^{38}$ Ibidem.}




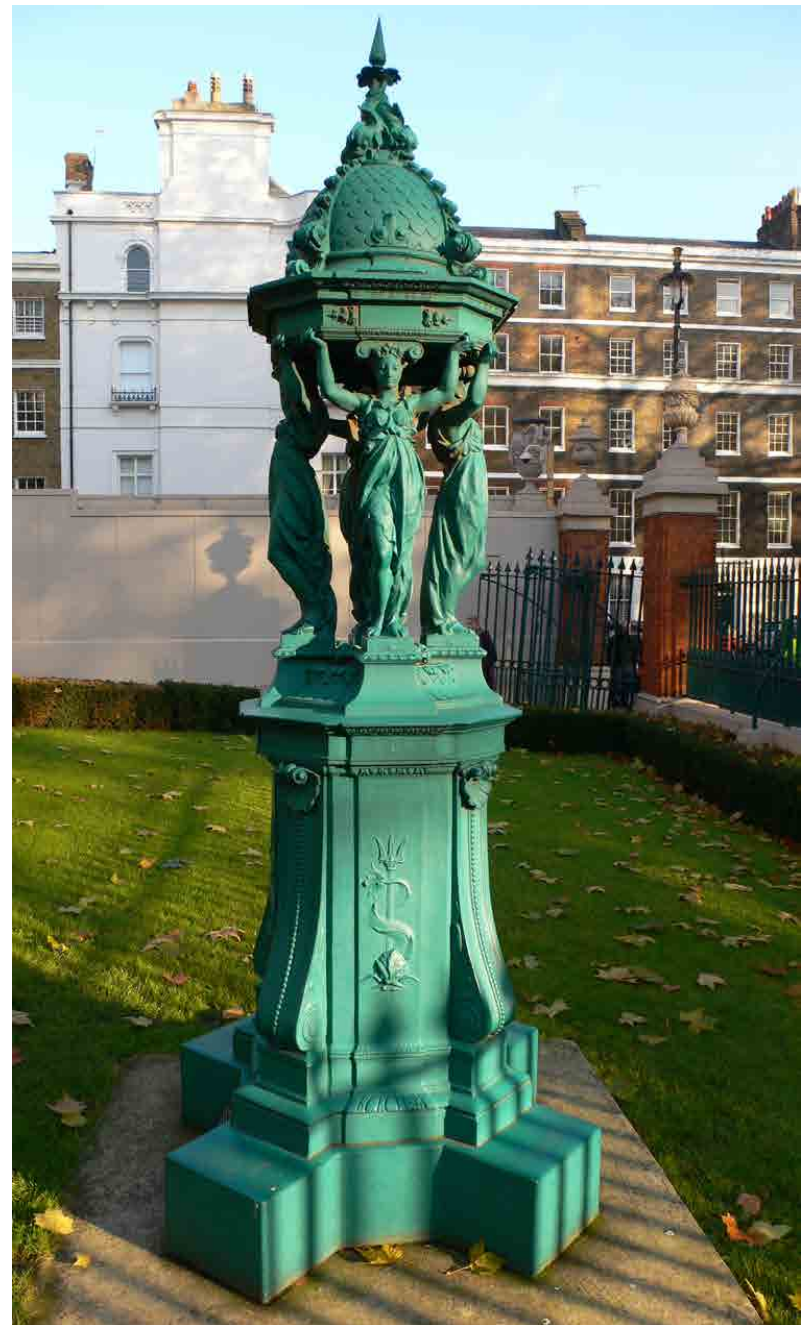

Abb. 13: Brunnen der „Metropolitan Drinking Fountain and Cattle Trough Association", 1904, London, Manchester Square. Foto: Wikimedia Commons, Justinc.

war die Spannbreite zwischen schlichteren und sehr aufwendigen Anlagen, je nachdem, wieviele Mittel der entsprechende Stifter bzw. die entsprechende Stifterin zur Verfügung gestellt hatte. In aller Regel waren es steinerne Brunnenanlagen, und es waren jeweils individuelle Schöpfungen. Das unterscheidet das vorbildhafte philanthropische Projekt in London von den Brunnen des Richard Wallace in Paris, die, aufgeteilt in die zunächst nur zwei Typen, industriell multipliziert wurden und technisch Eisengussarbeiten waren. Unter den noch stehenden Brunnen der Londoner Gesellschaft gibt es nur zwei

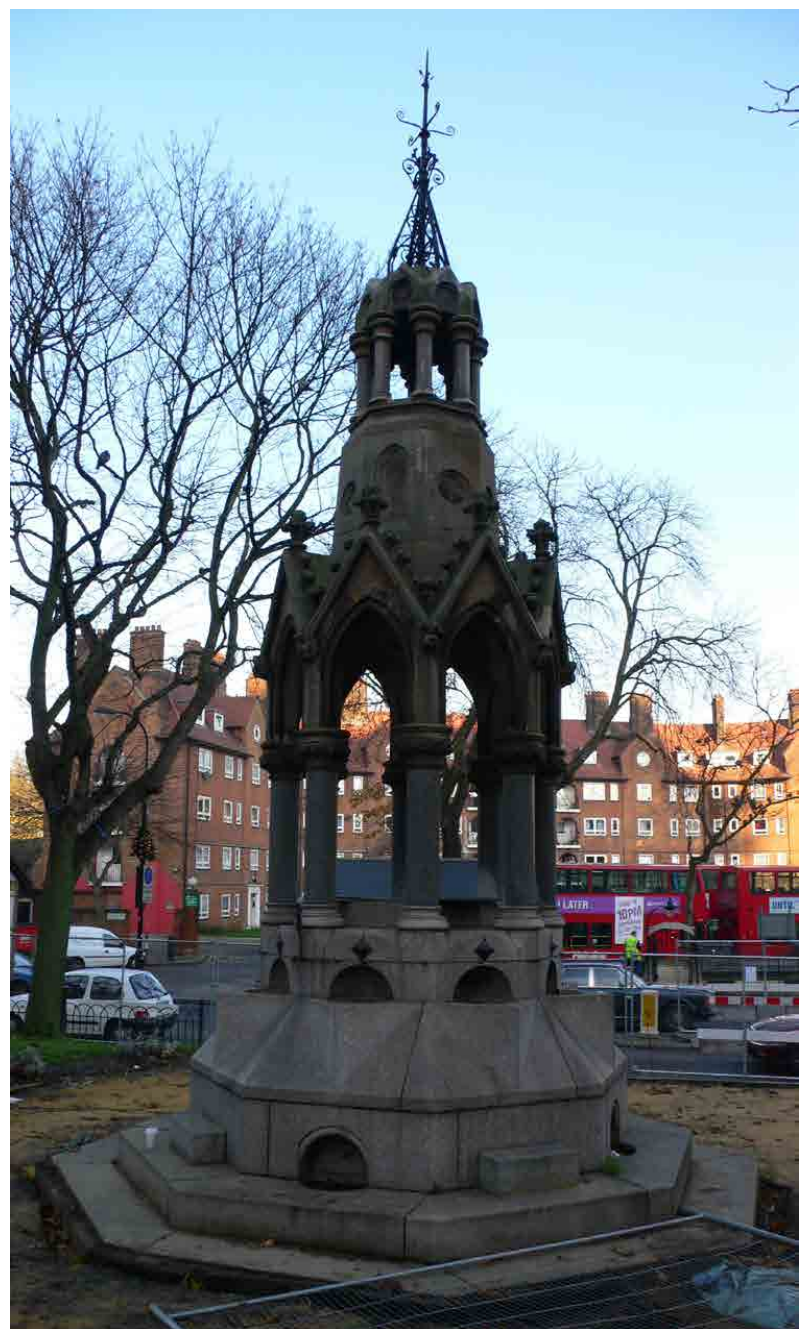

Abb. 14: Brunnen der „Metropolitan Drinking Fountain and Cattle Trough Association", 1880, London, South End Green. Foto: Wikimedia Commons, Justinc.

Eisengussbrunnen: den 1877 im Kirchgarten von St. Pancras errichteten (Abb. 12) und den späteren in Wimbledon. Und diese dürften unter dem Einfluss der Brunnen des Richard Wallace oder ihrer Nachfolger entstanden sein. Ausgeklammert sei der Brunnen am Manchester Square (nordöstlich vom Eingangs der Wallace Collection). (Abb. 13) Vier Jahre nach Eröffnung des Museums errichtete man ihn zur Erinnerung an Richard Wallace. Man muss ihn ausklammern, denn er ist auch in diesem Exemplar am Manchester Square ein französischer Brunnen, der französische Brunnen eines Engländers. 
Ein weiterer Unterschied: Häufig finden sich an den englischen Brunnen Bibelzitate, die das Brunnenwasser auf das Wasser des Lebens beziehen. Genannt sei eine Brunnenanlage, die 1880 errichtet wurde (South End Green), (Abb. 14). Eine Inschrift gibt die Aufforderung des Propheten Jesaja an die Durstigen weiter, zum Wasser des Heils zu kommen. „Everyone that thirsts come up to the waters" (Jsaias 55,1). Im Zusammenhang lautet der Text des Jesaja: „Zum Wasser kommet, ihr Durstigen all! Kommt, die ihr kein Geld habt, kaufet und esset ohne Geld und ohne Kaufpreis Wein und Milch!" Die Brunneninschrift bringt nur den ersten Teil der Jesaja-Stelle. Man tat gut daran. Jesaia spricht, wie zitiert, auch von Wein, der den Durstigen erwartet. Das hätte die „Metropolitan Drinking Fountain and Cattle Trough Association" nicht so gern gesehen. Bevor Gurney und Wakefield die Errichtung von Brunnen mit gefiltertem und gekühltem Wasser initiierten, musste man sich auf der Straße mit gewöhnlich verunreinigtem Wasser zufriedengeben. Gesünder war es unter diesen Umständen, seinen Durst mit Bier zu löschen, was aus anderen Gründen aber wieder ungesund sein konnte. Dieser andere Grund war eine weitere Motivation für die Gründung der „Metropolitan Free Drinking Fountain Association“. Sie war Teil der Antialkoholismus-Kampagne. $\mathrm{Ob}$ auch Richard Wallace seine Brunnen mit diesem moralischen und gesundheitsfördernden Anspruch ausgestattet wissen wollte, ist nicht auszuschließen. Explizit wird es zumindest nicht gemacht, und das hätte in das Paris der Dritten Republik auch nicht so recht gepasst.

In jedem Fall also sind die Brunnen des Richard Wallace in Paris gleich ihren englischen Voraussetzungen modern in Hinblick auf moderne Weisen der Wasserversorgung einer städtischen Bevölkerung und in Hinblick auf moderne Hygienevorstellungen; im Unterschied zur Mehrzahl der Londoner Brunnen modern zudem in Hinblick auf den Einsatz moderner industrieller Fertigung und moderner Materalien für die Verbesserung der Lebensqualität der Massen, modern schließlich in Hinblick auf die Aufgabe des individuellen Status eines Werks zugunsten multipler

\footnotetext{
${ }^{39}$ SAINT-SIMON. Zit. in: Art in Theory 1815-1900. An Anthology of Changing Ideas. Eds. HARRISON, CH. - WOOD, P. - GAIGER, J. Oxford - Malden 1998, S. 39.
}

Kunst. Doch, und damit komme ich auf die schon formulierte Frage zurück: sind diese Objekte auch Avantgarde-Kunst, und zwar nicht trotz des historistischen Rückgriffs auf die Kunstgeschichte des französischen 16. Jhs. und trotz der Trivialisierung hoher Kunst und sakraler Zwecke, sondern eben deswegen?

\section{Die Wallace-Brunnen als Avantgarde-Kunst}

Die Geschichte des Begriffs Avantgarde ist hilfreich: Zunächst ist Avantgarde ein militärischer Begriff, meint die Vorhut einer Truppe. Graf von Saint-Simon, Hauptvertreter des vormarxistischen französischen Sozialismus, den Marx als „Utopischen Sozialismus" etikettieren wird, eignete sich den Begriff an, um sein gesellschaftliches Ziel und die dafür nötige Allianz zu benennen. Künstler, Wissenschaftler und Industrielle müssten, so Saint-Simon, sich zusammenschließen, um gemeinsam das Los der Menschen zu verbessern. Die führenden Klassen seien nicht fähig, das Leid der unteren Klassen zu lindern. ${ }^{39}$ Deshalb bedürfe es, und in diesem Zusammenhang fällt der Begriff der „Avantgarde“, dieses Zusammenwirkens von Künstlern, Wissenschaftlern und Industriellen, die allein über die „Waffen“verfügten, die Gesellschaft zum Guten hin zu verändern. ${ }^{40}$ Ziel war, der größtmöglichen Zahl an Menschen das größtmögliche Maß an materiellen Gütern und an geistig / moralischen Freuden zu bereiten. ${ }^{41}$ Insbesondere in Hinblick auf letzteres kam innerhalb der avantgardistischen Allianz, der Kunst die führende Rolle zu.

Henry Jouin, der sich ab den 1870er Jahren als kunstliterarische Kapazität auf dem Gebiet der Skulptur profilierte, gab - sicher in der Nachfolge eines Saint-Simon - konkretere Hinweise, welche Rolle Skulptur in der modernen Arbeitswelt zu erfüllen hätte. Welcher Arbeiter gehe schon ins Theater? Gemälde im Museen zu sehen sei dem Arbeiter nur an seinen Ruhetagen möglich, und die nähmen mehr und mehr ab. Bald werde das Werkzeug Maschine den Maschinenmenschen zum Pendant bekommen. Allein der öffentliche Raum gehöre wirklich

\footnotetext{
${ }^{40}$ Ibidem, S. 40.

${ }^{41}$ Ibidem, S. 39.
} 
der arbeitenden Bevölkerung; die Skulptur sei die vorzügliche bildende Kunst im öffentlichen Raum. Somit sei die Skulptur die Kunst des Volkes. Daher seine Forderung nach mehr Skulptur im öffentlichen Raum: Man müsse ihn „mit Statuen bevölkern so wie er mit Arbeitern bevölkert ist. ${ }^{\text {" }} 22$

Skulptur im öffentlichen Raum war also eine zentrale soziale Forderung und sie hatte einen Auftrag: „Es (das Volk, HK) will, so Jouin, dass es (...) mitgenommen wird in eine höhere Welt. ${ }^{\text {"43 }}$ Die höhere Welt der Kunst im Louvre war dem Arbeiter zwar nicht verschlossen, aber eben kaum zugänglich - aufgrund der Arbeitszeiten und dem Bedürfnis nach Erholung an den wenigen arbeitsfreien Tagen, Erholung, deren Ort die Straße und weniger das elitäre Museum sein konnte. Die Dank moderner Produktionsmethoden mögliche Trivialisierung der Kunst der Museen brachte diese Kunst der Museen auf die Straße, auf die Plätze, in die Gärten, unter die arbeitende Bevölkerung. Ersetzbar ist deshalb der Begriff „Trivialisierung" durch den Begriff der Avantgarde - es geht um das Zusammenwirken des Künstlers und damit selbstverständlich auch der vom Künstler aufgerufenen kunsthistorischen Tradition, mit dem Wissenschaftler, der um die hygienischen Probleme der Trinkwasserversorgung weiß und Filtrieranlagen erfinden kann, und mit dem Industriellen, der allererst die technischen Voraussetzungen zu schaffen fähig ist.

Man kann dem Vorschlag von Henry Jouyn geteilt gegenüberstehen - es ist nicht klar, ob der von Jouin vorausgesehene „Maschinenmensch“ nicht doch nur kulturell stillgestellt werden sollte. In jedem Fall war mit dem Begriff „Avantgarde“ schon von Saint-Simon eine Kunst für alle angedacht, und die Straßenrenaissance der Wallace-Brunnen war Teil dieses Konzeptes. Die Brunnen waren im eigentlichen Sinne, wenn man auf die Begriffsgeschichte

${ }^{42}$ „C'est lui qu'il faut peupler de statues comme il est peuplé de travailleurs." JOUIN, H.: La sculpture au Salon de 1873. Paris 1874, S. 24-26.

43 „Il lui demande (...), de l'emporter dans un monde supérieur.“ JOUIN, H.: La Sculpture en Europe, 1878, précédée d'une conférence sur le génie de l'art plastique. Paris 1879, S. 18.

44 "Maritorne". JOUIN, H.: La Sculpture au Salon de 1882, in: JOUIN. H.: La sculpture aux Salons de 1881, 1882, 1883 et à und den sozialreformerischen Anspruch blickt, Avantgarde. Die künstlerische Avantgarde, die wir heute darunter verstehen, die klassische Moderne also, war demgegenüber, man muss es sich eingestehen, trotz der munter wiederholten Absicht, Kunst und Leben zu vereinen, von Anfang an eine elitäre Angelegenheit geblieben.

\section{II.}

\section{Brot auf dem Denkmalssockel}

Henri Jouins Apologie einer Kunst der Straße, einer Skulptur für den modernen Arbeiter, hätte auch die Bronze einschließen können, von der der zweite Teil dieses Beitrags handelt. Eine junge Frau, die auf dem Denkmalssockel im Square de la Tour Sant-Jacques im IV. Pariser Arrondissement von 1886 bis 1943 Brote austrug. Jouin kannte die Statue, und er lehnte sie ab. In seinen kunstkritischen Anmerkungen zur Skulpturenabteilung des Salons von 1882 sprach er dem Gipsmodell jede Schönheit ab, verurteilte die „Vulgarität" der Darstellung, und nannte die Dargestellte eine „Schlampe“. ${ }^{44}$ (Abb. 15, 16) Entschuldigt sah er diesen Verstoß gegen das auf dem Gebiet der Skulptur Angemessene auch nicht durch den Antike alludierenden Fünfzeiler aus der Feder Adrien Dézamys, der im offiziellen Ausstellungskatalog dem Eintrag für die Nr. 4248 angefügt ist. ${ }^{45}$ Das Sonett spricht von der Robustheit der Arbeiterin, von ihrer „banalen Schürze“ und rühmt sie als ,,authentische Plebejerin“. Sie sei, so heißt es abschließend, „Der moderne Widerschein der antiken Ceres“".46 Jouins Indignation wird verständlich, wenn man sich erinnert, welche Verpflichtung seiner Ansicht nach die einfache Bevölkerung der Skulptur als Kunst der Straße auferlegt: „Es (das Volk, HK) will, dass es (...) mitgenommen wird in eine höhere Welt. ${ }^{\text {c47 }}$

l'Exposition nationale de 1883. Paris 1884, S. 39-55, hier S. 52.

${ }^{45}$ Ibidem, S. 52.

46 "Robuste“, „tablier banal“, „Le moderne reflet de la Céres antique“. Explication des Ouvrages de Peinture, Sculpture, Architecture, Gravure et Lithographie, des Artistes vivans, exposés au Palais des Champs-Élysée, le 1er mai 1882. Paris 1882, Reprint in: Ed. SANCHEZ, P. Les Catalogues des Salons, XIII (1880-1883) (...). Paris 2009, S. 375. 


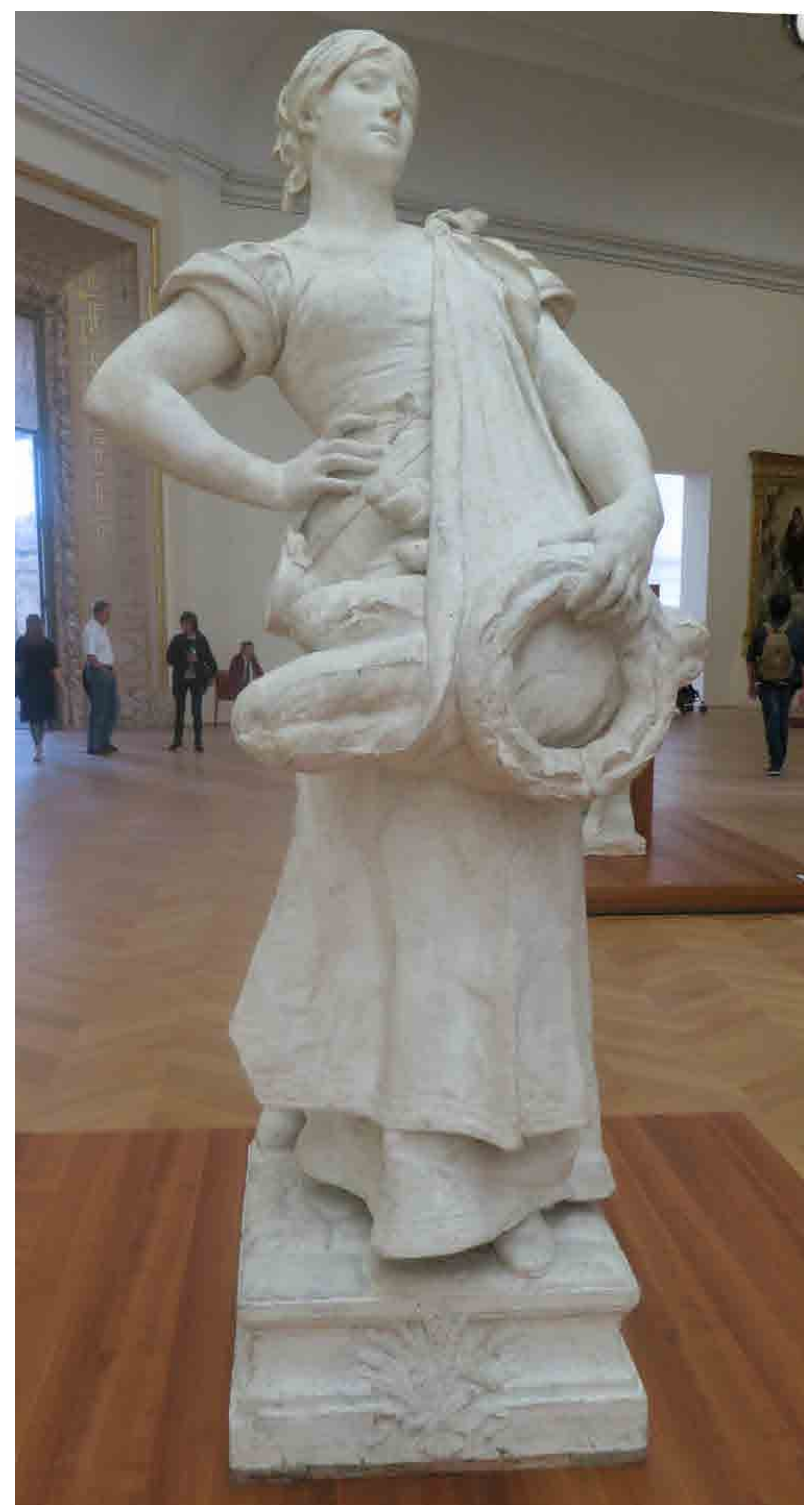

Abb. 15: Coutan, Jules, Die Brotaussträgerin, 1881, Gips, Paris, Musée du Petit Palais (1886 Einweibung des Denkmals). Foto: Hans Körner.

Nicht das Material, nicht der Produktionsprozess, nicht die Funktion macht den Schöpfer dieser Plastik, Jules Coutan, zu einem programmatischen ,Bildhauer des modernen Lebens', sondern die ikonographie. Anders als in den historistischen Wallace-Brunnen wird in diesem Denkmal Modernität zum Thema. Aus dem Kanon der Moderne blieb die Statue trotzdem oder eben deshalb ausgeschlossen.

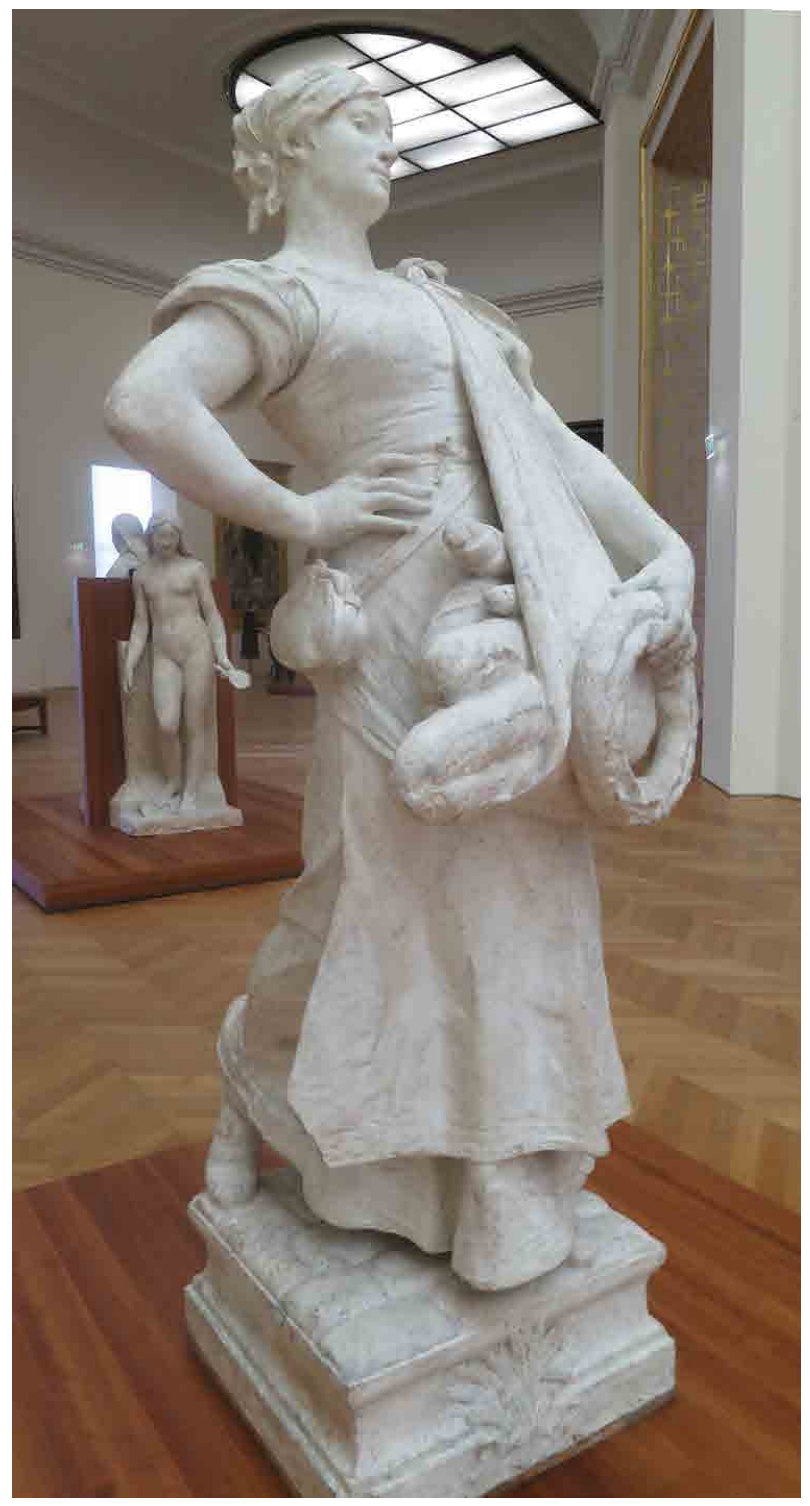

Abb. 16: Coutan, Jules, Die Brotaussträgerin, 1881, Gips, Paris, Musée du Petit Palais (1886 Einweihung des Denkmals). Foto: Hans Körner.

\section{Die Apotheose einer proletarischen Tätigkeit}

Eine junge Frau hat ein schürzenartiges Tuch an ihrer linken Schulter zusammengeknotet, in das sie ihre Waren eingeschlagen hat. Dickere und dünnere längliche Brote v. a., frühe Dokumente der französischen Baguette. In der Linken hält sie ein 
zum Kranz geflochtenes Brot - „Couronne“ ist der entsprechende französische Name. Die Last ist schwer. Bis zu 100 Pfund konnten die Brote wiegen, die eine Brotaussträgerin zu schleppen hatte. ${ }^{48}$ Die Körperhaltung ist entsprechend. Die Frau beugt sich zurück, schiebt den Oberkörper nach vorn, eine Haltung, die dem Tragen schwerer Lasten vor dem Leib gemäß ist. Sie hat Kraft, das sieht man.

Wir wissen, welches Arbeitspensum sie abzuleisten hatte: Gegen vier / fünf Uhr morgens machte die Pariser Brotaussträgerin sich auf den Weg, war insofern oft die erste Frau, die den angetrunkenen oder betrunkenen Nachtschwärmern am Morgen auf der Straße begegnete. ${ }^{49}$ Die Brote brachte sie in die Wohnung der Kunden oder legte sie, bedeckt mit einem Blatt Papier als nicht immer zureichenden Schutz vor hungrigen Hunden und Katzen vor die Wohnungstür. ${ }^{50}$ Nicht selten wohnten die Kunden in den oberen Stockwerken. Octave Uzanne schätzte 1910 die Zahl der Stockwerke, die eine Pariser Brotausträgerin an einem Arbeitstag durchschnittlich hochstieg, auf 400 bis $500 .{ }^{51}$ Sie musste kräftig sein. Mme. A. de Paquet-Mille publizierte im ausgehenden 19. Jh. eine pädagogische Anleitung für junge Mädchen auf der Suche nach einem Beruf. Sie wies in ihre Ausführungen zum Beruf der Brotausträgerin auf den frühen Arbeitsbeginn hin, auf den zu erwartenden Verdienst - zwischen 18 und 22 fr. in der Woche (plus zwei Pfund Brot) - und sie betonte die für den Beruf erforderlichen physischen Vorausset-

${ }^{47}$ „Il lui demande (...), de l'emporter dans un monde supérieur.“ JOUIN 1879 (wie Anm. 43), S. 18.

${ }^{48}$ KAPLAN, S. L.: La France et son pain. Histoire d'une passion. Entretiens avec Jean-Philippe de Tonnac. Paris 2010, S. 155.

${ }^{49}$ UZANNE, O.: Parisiennes de ce temps en leurs divers milieux, états et conditions: Études pour servir à l'bistoire de femmes, de la société, de la galanterie française, des moeurs contemporaines et de l'égoïsme masculin (...). Paris 1910, S. 150.

${ }^{50}$ Ibidem, S. 151.

${ }^{51}$ Ibidem.

52 „des forces physiques presque égales à celles de l'homme.“ PAQUET-MILLE, A.: Nouveau Guide pratique des jeunes filles dans le choix d'une profession. Paris 1891, S. $181 \mathrm{f}$. zungen: diese müssten ,fast denen der Männer gleich sein. “52 Marcel Arpin schätzte den Wochenlohn einer Brotaussträgerin vor 1914 noch geringer ein: auf 14 bis 18 fr. in der Woche. (Männliche Brotausträger verdienten gut das Doppelte. $\left.{ }^{53}\right)$ Für das „Déjeuner“, das im Verlauf der ersten Hälfte des 19. Jhs. zunehmend die Rolle des Dîner einnahm, das wiederum das Souper ersetzte (oder zum zweiten - üppigen und champagnerbegleiteten - mitternächtlichen Abendessen machte), ${ }^{54}$ lieferte die Brotausträgerin auf weiteren „tournées“ warme „pains viennois“ und anderes Gebäck. ${ }^{55}$ Gegen 12.30 Uhr war das Arbeitspensum gewöhnlich bewältigt. Sie ging entweder nach Haus, um für ihre Familie den Haushalt zu führen oder arbeitete weiter als Verkäuferin in der Bäckerei, die sie als Brotausträgerin angestellt hatte. ${ }^{56}$

Nicht nur physisch hatte die Brotausträgerin einiges mitzubringen, sie musste intelligent sein. Der Bildhauer konnte diese Eigenschaft schwerlich anschaulich machen, aber auch hier helfen die Texte der Zeitgenossen, die von den nötigen Fertigkeiten berichten, die vielfältigen Sorten von Brot und Gebäck ${ }^{57}$ und die diversen Preise auseinanderzuhalten, zu merken, welcher Kunde welche Geschmacksvorlieben hat, wer was bestellt hatte, welchen Zahlungsmodus der einzelne Kunde bevorzugte (wöchentliche / monatliche Zahlung), ob und wieviel Kredit wem gewährt werden durfte. ${ }^{58}$ Die Brotaussträgerin Coutans ist stolz auf ihren (in der Realität sehr schlecht bezahlten) Beruf. Der nach

${ }^{53}$ ARPIN, M.: Historique de la meunerie et de la boulangerie depuis les temps prébistoriques jusqu'à l'année 1914. T. II: Boulangerie. Paris 1948, S. 99.

${ }^{54}$ ARON, J.-P.: Le mangeur du XIXe siècle. Paris 1973, S. 207 ff.; ANDERSEN, W: Manet. The Picnic \& the Prostitute. Boston Genf 2005, S. 67.

55 ARPIN 1948 (wie Anm. 53), S. 100.

${ }^{56}$ Ibidem, S. 100.

${ }^{57}$ Eine Übersicht gibt EGROT, M.: La Boulangerie parisienne sous le Second Empire. In: Actualité de l'bistoire, No 14, 1956 , S. 12-29, hier S. 28 f.

${ }^{58}$ CHEVALLIER, J.: Porteuse du pain. In: Dictionnaire universel du pain. Ed. TONNAC, J. PH. DE. Paris 2010, S. 888-889, hier S. 888. 


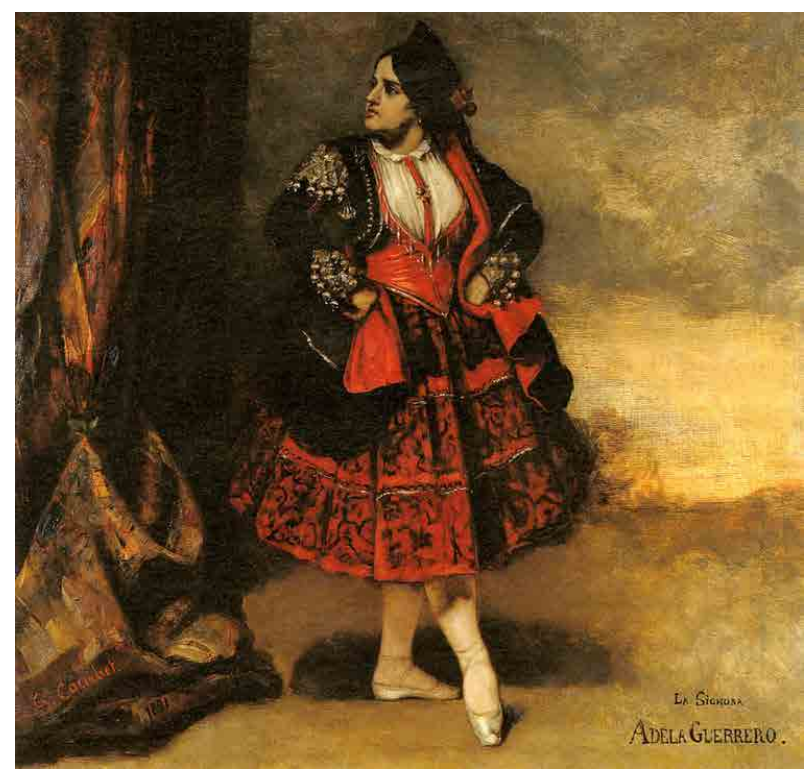

Abb. 17: Courbet, Gustave, Spanische Tänzerin (Adela Guerrero), 1851, Brüssel, Musée Royaux des Beaux-Arts de Belgique. Foto: La Nuit espagnole. Flamenco, avant-garde et culture populaire 1865-1936. Ed.: Rio, G. Paris 2008, S. 23.

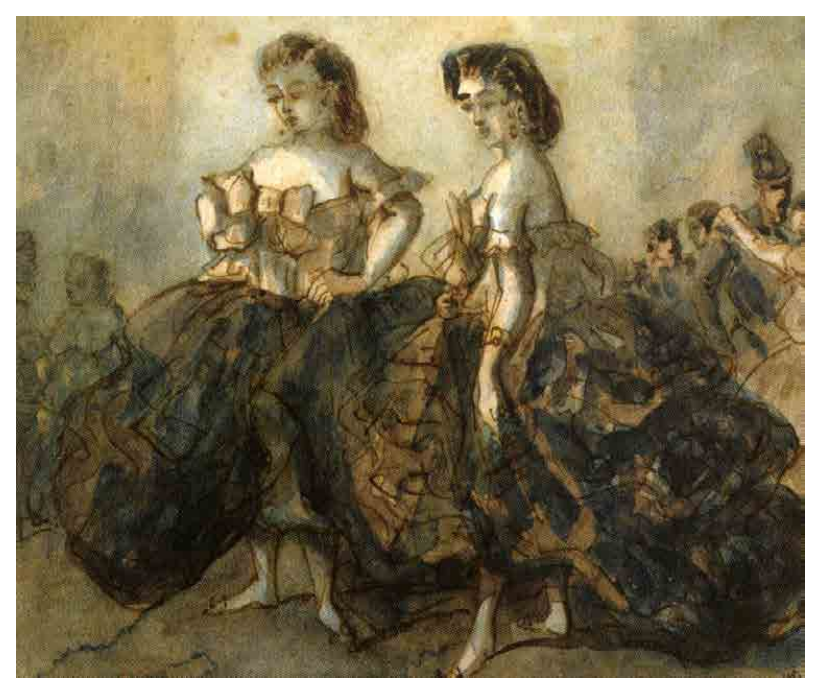

Abb. 18: Guys, Constantin, Zwei Frauen, um 1850 - 1860, Paris Musée d'Orsay. Foto: Musée d'Orsay: Manet. Inventeur du Moderne, Katalog der Ausstellung. Paris 2011, S. 143.

${ }^{59}$ Dazu und zum folgenden WILKENS, M.: ... er vergaß sich zuweilen so weit, mich , die Spanierin', , die Fremde' zu nennen!" Das Bild der spanischen Frau im Frankreich des Zweiten Kaiserreiches. vorn geschobene Unterleib balanciert, wie vorhin gesagt, das Gewicht der vor dem Körper getragenen Last aus, manifestiert aber auch Dominanz, und diesen Dominanzanspruch verrät zusätzlich der in die Seite gestemmte rechte Arm. Diese Geste war in Frankreich hoch aufgeladen. So präsentiert sich Ludwig XIV. in Hyacinthe Rigauds Staatsporträt. Im französischen 19. Jh. wird diese Handgeste zum Signum der selbstbewussten, der modernen Frau.

Spanierinnen wurden bevorzugt mit der Dominanzgeste der in die Hüfte gestemmten Hand dargestellt. Dass gerade die Spanierin in französischen Bildern des 19. Jhs. so abgebildet wurde, hat wohl auch mit den Erfahrungen zu tun, die die napoleonischen Besatzungstruppen mit den rebellierenden Spaniern, darunter (wie es hieß: männlich) agierenden spanischen Widerstandskämpferinnen, machen mussten. ${ }^{59}$ Courbets „Spanische Tänzerin" erinnert noch mit ihrem kriegerischen Namen „Guerrero" daran; (Abb. 17) in Edouard Manets Bildnis der Tänzerin einer in Paris gastierenden spanischen Revue, Lola de Valence, ist das Trauma des spanischen Aufstands gelöscht, aufgehoben in das Bild einer selbstbewussten, physisch und psychisch starken, sexuell selbstbestimmten und deshalb sexuell freizügigen Frau. Auch in Prosper Mérimées Novelle und Georges Bizets Oper „Carmen“ sind das die dominanten Charakterzüge der spanischen Frau.

Es war eine klischeehafte und trotzdem im kulturellen Kontext des späteren 19. Jhs. eine innovative Ikonographie. Nicht zuletzt entlang des Bildes der Spanierin formierte sich eine moderne künstlerische Konzeption der modernen Frau, was zunächst hieß: der modernen Pariserin. Ein anderes Leitbild für die moderne Frau war die Kurtisane. Auch hier verschränken sich sexuelle Freizügigkeit, maskuliner Habitus und Selbstbewusstsein. Edouard Manets „Olympia“ ist das Paradebeispiel. Anschließen könnte man das Bildnis der Mätresse des Fotografen Nadar, auch hier eine liegende Frau - der Begriff der „Großen Horizontalen“ war synonym mit dem der Kurtisane -, und hier kommt zum lasziven Lie-

Eine klischeegeschichtliche Untersuchung. Frankfurt 1994, S. 95 ff.; KÖRNER, H.: Edouard Manet. Flaneur, Dandy, Maler. München 1996, S. $37 \mathrm{ff}$. 
gemotiv, zum selbstbewusstein Blick auch noch die spanische Bekleidung, im übrigen Männerkleidung, die Tracht eines Torero.

An Selbstbewusstsein steht die proletarische Brotaussträgerin Coutans, wie Blick und Pose verraten, hinter den eben genannten gefeierten Tänzerinnen und Kurtisanen kaum zurück. Wie ist es mit dem sexuellen Appell, der zumindest bei Manet zum Signum der selbstbewussten und selbstbestimmten modernen Frau gehört? Die Pose des zum Betrachter hin vorgeschobenen Unterkörpers ist nicht nur zweideutig, sondern dreideutig: Ausbalancieren der Last, Ausdruck von Selbstbewusstsein, aber eben doch auch ein erotisches Signal. Letzteres stimmt durchaus zum Klischee, in das solche Frauen gepresst wurden, wobei anzumerken ist, dass Männer damals (heute wohl auch bisweilen noch) der Vorstellung anhängen konnten, dass Frauen selber daran Schuld tragen, wenn sie zum verfügbaren Sexualobjekt werden. Und die Brotaussträgerin wurde sexuell bedrängt, belästigt, auch gelegentlich vergewaltigt. Unterwegs schon zu nächtlicher Zeit, oft allein in der Wohnung mit dem Kunden - war die Brotausträgerin eine literarisch schon im 18. Jh. als solche beschriebene leichte sexuelle Beute. ${ }^{60}$ Wie es der Brothistoriker Steven L. Kaplan formulierte: „War sie nicht die Hure des Kundes, dann oft die ihres Arbeitgebers, so sagte man. ${ }^{\text {"61 }}$ Zur Bekräftigung, wie fest sich das Klischee gesetzt hatte, zitierte Kaplan, die Aussage, mit denen man Bäckermeister gerne provozierte: Er sei jemand, der seiner Brotausträgerin Kinder mache. ${ }^{62}$ Gerichtsakten bestätigen, dass die Provokation auf tatsächliche Fälle rekurrierte.

${ }^{60}$ KAPLAN, S. L.: The Bakers of Paris and the Bread Question 1700-1775. Durham - London 1996, S. 108 f.; CHEVALLIER 2010 (wie Anm. 58), S. 888.

${ }^{61}$ „Si elle n'était pas la putain du client, elle était souvent celle de son maître, disait-on. “KAPLAN 2010 (wie Anm. 48), S. 156.

${ }^{62}$ Ibidem, S. 156.

${ }^{63}$ „Le beau est fait d'un élément éternel, invariable (...) et d'un élément relatif, circonstanciel, qui sera, si l'on veut (...) l'époque, la mode, la morale, la passion. BAUDELAIRE, CH.: Le peintre de la vie moderne (1863). In: BAUDELAIRE, CH.: Curiosités esthétique. L'art romantique et autres Oeuvres critiques. Ed: LEMAITRE, H. Paris 1962, S. 453-502, hier S. 455 f. Dt.
Um die Modernität von Jules Coutans „Brotausträgerin" bestätigt zu bekommen, genügt die Lektüre von Charles Baudelaires „Peintre de la vie moderne“, eines Gründungstextes der Moderne. Baudelaire feierte Constantin Guys als den „Maler des modernen Lebens“", weil Guys Welt die moderne Stadt sei, Paris selbstredend, die Stadt mit ihren Boulevards, den Cafés, dem Gewimmel der Menschenmenge, der käuflichen Liebe. (Abb. 18) Die Brotausträgerin gehörte zu dieser modernen Stadt.

Der traditionellen ästhetiktheoretischen Ambition, das zeitlos Schöne zu bestimmen, stellte Baudelaire in seinem Text, der zuerst Ende 1863 in drei Folgen im „Figaro“ publiziert wurde, eine Definition des Schönen gegenüber, die sich aus einem statischen und einem transitorischen Element zusammensetzt: „Das Schöne besteht aus einem ewigen, unveränderlichen Element (...) und einem relativen, von den Umständen abhängigen Element, das, wenn man so will, (...) die Epoche, die Mode, die Moral, die Leidenschaft sein wird. “63 Das transitorische Element am Schönen ist die Moderne, die Constantin Guys, der Chronist des ,modernen Lebens“, zum Thema erhob: „Die Modernität ist das Vergängliche, das Flüchtige, das Zufällige“، ${ }^{64}$ Gegenwärtigkeit ist für sich bereits ein ästhetischer Wert: „Das Vergnügen, das uns die Darstellung der Gegenwart verschafft, entspringt nicht nur der Schönheit, worin sie sich kleiden mag, sondern auch ihrer wesentlichen Eigenschaft als Gegenwart. ${ }^{\text {c65 }}$

Liest man aus der von Baudelaire zum Defitionskriterium erhobenen Beweglichkeit der Moderne nicht nur die Affirmation der historisch raschen

n. BAUDELAIRE, CH.: Der Maler des modernen Lebens (1863). In: BAUDELAIRE, CH.: Aufsätze zur Literatur und Kunst 1857-1860 (= Sämtliche Werke / Briefe. Eds: KEMP, F. - PICHOIS, P. in Zusammenarbeit mit DROST, W., Bd. 5). München - Wien 1989, S. 213-258, hier S. 215.

${ }^{64}$ „La modernité, c'est le transitoire, le fugitif, le contingent.“ BAUDELAIRE 1962 (wie Anm. 63), S. 467. Dt. n. BAUDELAIRE 1989 (wie Anm. 63), S. 226.

65 „Le plaisir que nous retirons de la représentation du présent tient non seulement à la beauté dont il peut être revêtu, mais aussi à sa qualité essentielle de présent." BAUDELAIRE 1962 (wie Anm. 63), S. 454. Dt. n. BAUDELAIRE 1989 (wie Anm. 63), S. 214. 


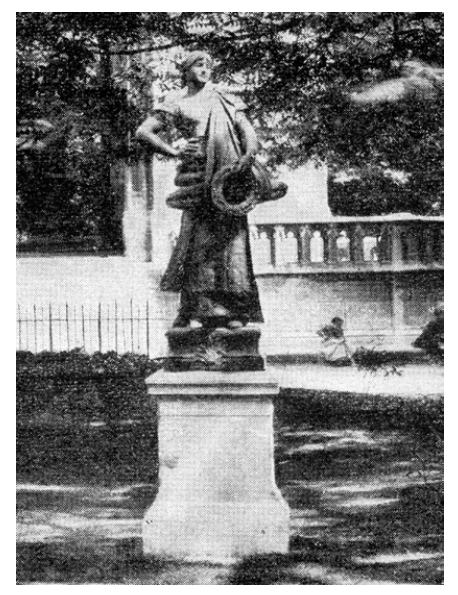

Abb. 19: Coutan, Jules, Die Brotaussträgerin, 1886 Einweibung des Denkmals, Bronze, ehem. Paris, Square Tour Saint-Jacques. Foto: Clément Maurice, 1897 - Wiki.https:/ / fr.m.wikipedia.org/wikil Fichier:Clément_Maurice_Paris_en_plein_air, BUC,_1897,120_detail,_. La_porteuse_de_pain.jpg.

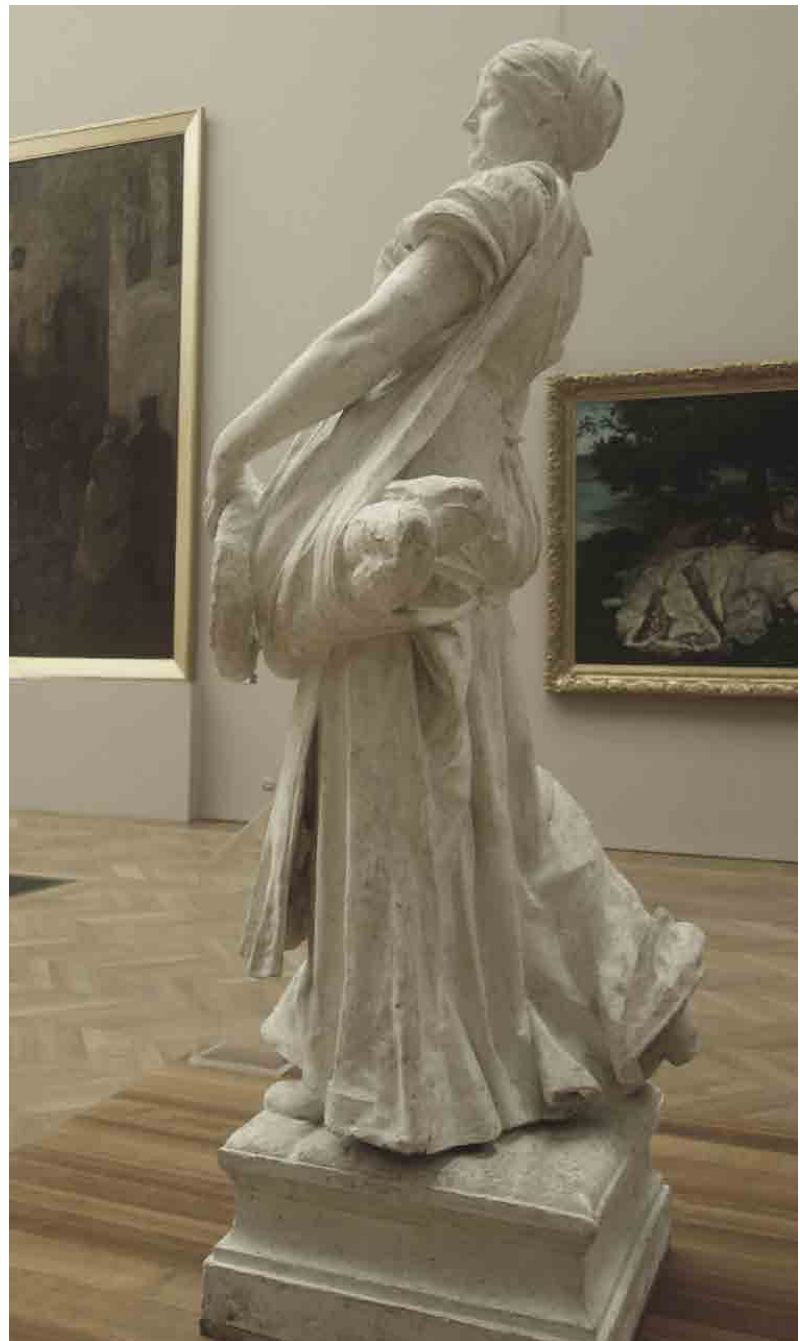

Abb. 20: Coutan, Jules, Die Brotaussträgerin, 1881, Gips, Paris, Musée du Petit Palais (1886 Einweihung des Denkmals). Foto: Wikimedia Commons.
Stilwechsel, des raschen Wechsel der Moden und der Verhaltensweisen heraus, sondern konzediert Baudelaire, grundsätzlich Moderne mit Bewegung und Übergänglichkeit zu konfundieren, dann ist Coutans „Brotaussträgerin“ nicht allein von Baudelaires Moderne-Definition betroffen, weil sie 1881 Gegenwart ist, Pariser Gegenwart, sondern auch, weil sie als Figur bewegt ist. Sie schreitet energisch aus. Das ist alles andere als selbstverständlich. Die Stadt Paris hatte Jules Coutans Statue angekauft, um sie auf einen Denkmalssockel im Square de la Tour Sant-Jacques zu stellen. (Abb. 19, 20) Der Terminus „Statue“ kommt vom Stehen nicht vom Gehen. Schon insofern war Coutans „Brotausträgerin“ ein modernes Kunstwerk, das umso mehr, als die von Ästhetiktheoretikern des frz. 19. Jhs. als grundsätzlich gattungsspezifisch unangemessen verurteilte Thematisierung von Mobilität in einer Statue sich nun sogar auf dem Denkmalssockel abspielte. ${ }^{66}$ Für Charles Baudelaire, für den Autor des „Peintre de la vie moderne“, hätte diese Statue Coutans die Kriterien der modernen Schönheit erfüllt, zumal er ausdrücklich darauf hinwies, dass Bildhauer, wären sie dem „modernen Leben“ aufgeschlossen genug, auch und gerade auf dem sozialen Bodensatz würdige Modelle finden würden. Baudelaire dachte an Prostituierte, doch die Übertragung auf eine Proletarierin wie die Pariser Brotaussträgerin ist zulässig: „Manchmal finden sie ungesuchte Haltungen von einer Kühnheit und einem Adel, die den wählerischten Bildhauer bezaubern würden" “. ${ }^{67}$

Jules Coutans „Brotausstägerin“ ist gegen alle anderslautenden Erzählungen des Faches Kunstgeschichte, ein modernes Bildwerk. Im übrigen schon aus dem schlichten Grund, weil sie sich nicht in einem antiken Peplos oder Chiton, auch nicht nackt, veröffentlicht. Noch im späten 19 . Jh. verwahrten

\footnotetext{
${ }^{66}$ Armand Dayot (Pseudonym: Jean Mériem) sah in der Spannung zwischen dem raschen Ausschreiten der Figur und ihrer „eternelle immobilité“ dagegen eine Qualität, die dazu beitrug, dass Coutans „figure est une des oeuvres les plus intéressantes et les plus vivantes du salon." MÉRIEM, J.: Tableaux \& Statues (Salon de 1882). Paris 1882, S. 151 f.

67 „Parfois elles trouvent, sans les chercher, des poses d'une audace et d'une noblesse qui enchanteraient le statuaire le plus délicat." BAUDELAIRE 1962 (wie Anm. 63), S. 498. Dt. n. BAUDELAIRE 1989 (wie Anm. 63), S. 254.
} 
sich maßgebliche Künstler und Ästhetiktheoretiker - Auguste Rodin auch ${ }^{68}$ - gegen das zeitgenössische Gewand in der Skulptur. Wenn etwas als unakademisch gelten durfte dann eben das: eine Figur in zeitgenössischem Kostüm.

\section{Ein moderner Körper}

Sie trägt moderne Kleidung, und, was man davon nicht abtrennen kann, sie hat einen modernen Körper. ${ }^{69}$ Es ist, wie man unschwer sehen kann, ein korsettierter Körper. Die Taille ist eng geschnürt, in betontem Gegensatz zu Über- und Unterkörper eine Wespentaille. Wenn ich darauf hinweise, dass man den Körper von der Kleidung nicht abtrennen dar, dann auch deshalb, weil die enge Schnürung des Korsetts, wenn es über einen längeren Zeitraum hinweg getragen wird, Spuren, am Körper hinterlässt, wenn auch nicht immer so im Wortsinne eindrückliche wie in Falguières „Tänzerin“, (Abb. 21). ${ }^{70}$ Solche Spuren des Korsetts noch am unbekleideten Körper wurden, sobald sich diese in der Aktskulptur manifestierten oder ahnen ließen, von der Mehrzahl der Kunstkritiker des 19. Jhs. verurteilt und einhellig als Signum des modernen, durch Kleidung, und das heißt, gesellschaftlich modellierten Körpers erkannt. Der Soziologe Thorstein Veblen, analysierte im frühen 20. Jh. das Korsett als hochschichtiges Phänomen, als Strategie, um die Frau auf ihre Rolle als passives Luxusgeschöpf festzulegen. Veblen ist nur eingeschränkt rechtzugeben. Das Korsett erleichtert das Atmen sicher nicht, macht aber anders als Veblen meinte, nicht arbeitsunfähig. Industrielle Fertigung hatte seit der Mitte des 19. Jhs. dieses Stück Unterkleidung selbst für die niederen Klassen erschwinglich werden lassen. Einfache Arbeiterinnen trugen Korsett, und sie trugen es bei der Arbeit. ${ }^{71}$ Die Funktion des Korsetts als soziales Distinktionsmerkmal trat zurück. Seine emblematische Funktion für Modernität blieb demgegenüber klassenübergreifend

${ }^{68}$ LUDOVICI, A. M.: Personal Reminiscences of Auguste Rodin. London 1926, S. $111 \mathrm{f}$.

${ }^{69}$ Das Gesicht allein schon sei ein modernes Gesicht. „Le visage, à lui seul, est un morceau charmant dans sa juste et vivante expression moderne. "MÉRIEM 1882 (wie Anm. 66), S. 151.

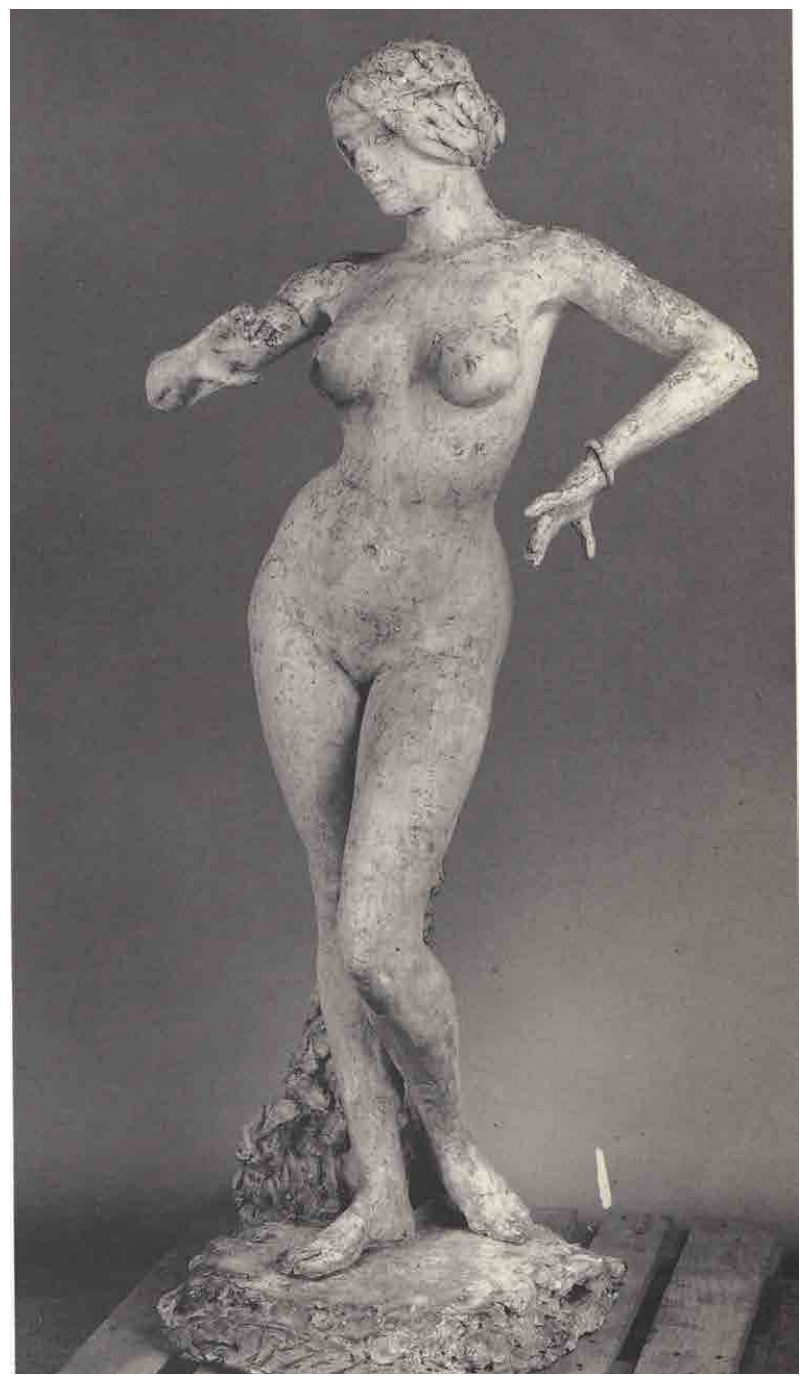

Abb. 21: Falguière, Alexandre, Die Tänz̧erin, 1896 (Gips), Paris, Musée d'Orsay. Foto: Abend, S. - Körner, H. (Hg.), Der schöne Mensch und seine Bilder, München 2017, S. 65.

bestehen. Ebenfalls seit der Jahrhundertmitte hatte die Industrie das zeitraubende und fremde Hilfe erfordernde Schnüren überflüssig werden lassen.

70 Zum folgenden KÖRNER, H.: Kunstkritik als Körperkritik. Die ,natürliche Schönheit und die gesellschaftliche Schönheit in der französischen Skulptur des 19. Jahrhunderts. In: Der schöne Mensch und seine Bilder. Eds.: ABEND, S. - KÖRNER, H. München 2017, S. 38-69.

${ }^{71}$ STEELE, V.: The Corset. A Cultural History (2001). New Haven - London 2003, S. 49. 


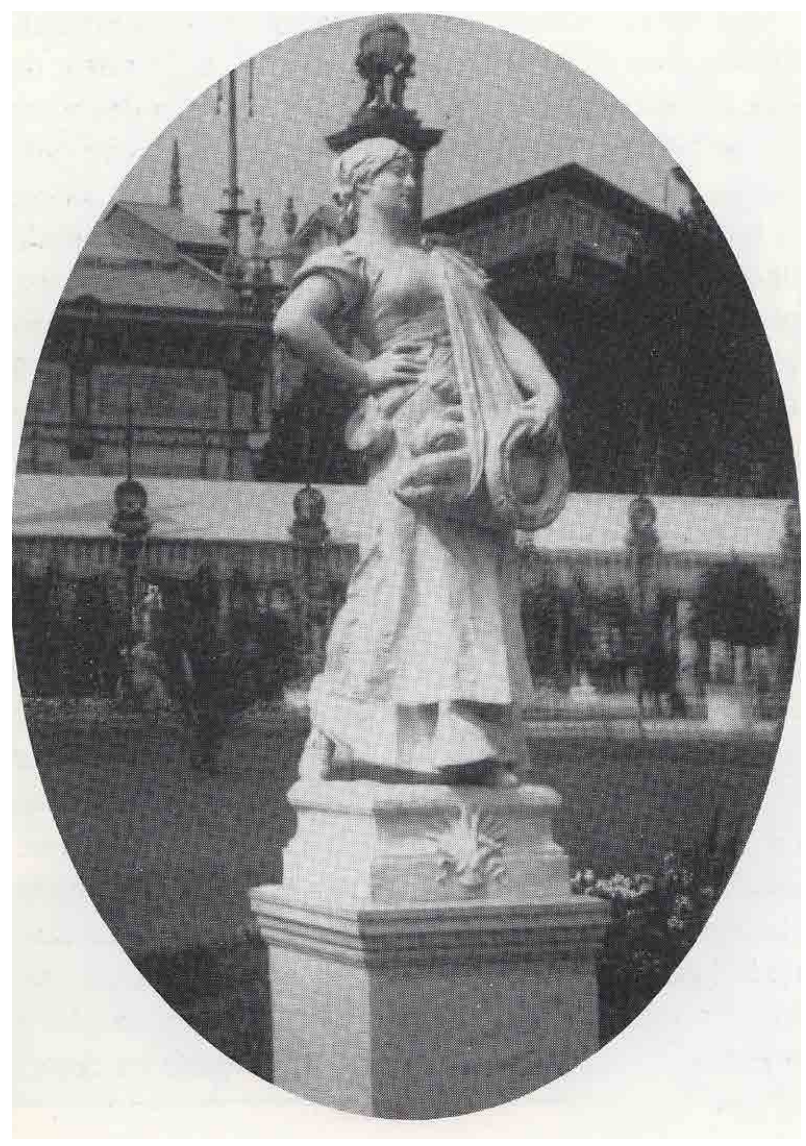

Abb. 22: Coutan, Jules, Die Brotaussträgerin, 1881 (Gips) auf der Weltausstellung 1889. Foto: Quand Paris dansait avec Marianne, Katalog der Ausstellung, Paris. Eds.: Grout, G. - Imbert, D. Paris 1989, S. 262.

Man konnte jetzt Korsetts erwerben, die auch ohne fremde Hilfe geschlossen werden konnten: auch das eine Bedingung der Möglichkeit der sozialen Entgrenzung.

Coutans Statue entfaltet ihr emanzipatorisches Potential im Rahmen der Denkmalspolitik der Stadt Paris in der „Dritten Repubik“. 1889 im Rahmen der

\footnotetext{
${ }^{72}$ IMBERT, D.: Les allées du Champ-de-Mars: Le square et la statue. In: Quand Paris dansait avec Marianne 1879-1889. Katalog der Ausstellung, Paris, Musée du Petit Palais 1989. Paris 1989, S. 252-267, hier S. 253.

${ }^{73}$ Ibidem, S. 252 f.

${ }^{74}$ BUROLLET, TH.: Le Dépot des sculptures de la Ville de
}

Weltausstellung präsentierte die Kommune die in den vorhergehenden Jahren angekauften Plastiken, die dafür bestimmt waren, oder bereits ihre Bestimmung erfüllten, die Plätze, Straßen, Parks und die Squares von Paris auszustatten. 84 Bronzeplastiken, Marmorskulpturen, v. a. aber Gipsmodelle, die man für die Aufstellung im Freien präpariert hatte, ${ }^{72}$ waren Richtung Tour Eiffel aufgereiht. ${ }^{73}$ Coutans „Brotaussträgerin“", 1882 nach der Ausstellung der Gipsfigur im „Salon“ von der Stadt angekauft, war dabei, als Denkmal einer Arbeiterin, als Denkmal und Kunstwerk für Menschen, deren kultureller Raum Straße, Platz und öffentliche Grünanlage waren, als modernes Kunstwerk mit modernem Thema. (Abb. 22)

Das Anliegen der vorliegenden Publikation ist es nicht, die klassische Moderne, die sich im Widerstand auch gegen Künstler wie Jules Coutan formiert hat, zu diskreditieren, doch sollte auch dieser ,anderen Moderne' Gerechtigkeit widerfahren werden. Das Pariser Musée du Petit Palais bemüht sich seit längerem darum. Von den Künstlern, die einen Denkmalsauftrag erhielten, erwarb die Stadt Paris immer auch das Gipsmodell. ${ }^{74}$ Paris besitzt deshalb einen großen Fundus an solchen Gipsen, und die Zahl der davon in der ständigen Sammlung des Petit Palais gezeigten, ist erfreulich hoch. Coutans „Brotausträgerin“ ist im Petit Palais präsent, als Gipsmodell: das Denkmal gibt es nicht mehr.

Die Bronzefigur, die 1886 im Square de la Tour Sant-Jacques im IV. Arrondissement eingeweiht wurde, war um 1943 wie die meisten Bronzen auf und an Pariser Denkmälern eingeschmolzen worden. 127 Denkmäler wurden ihrer Bronzefiguren beraubt und so ganz oder teilweise vernichtet. ${ }^{75}$ Es war nicht die deutsche Besatzungsmacht, wenn es auch ohne ihre Billigung gewiss nicht hätte geschehen können; es war die mit den Nationalsozialisten kollaborierende Vichy-Regierung, die die entsprechenden Anweisungen erteilte. Im Herbst 1941 ordnete Marschall

Paris ou La Survie de la statuaire parisienne. In: Gazette des Beaux-Arts, 12e année, 6e période, t. 104, 2, 1979, S. 113-124, hier S. 116.

75 Siehe den Katalog der zerstörten Bronzen in BIZARDEL, Y.: Les statues parisiennes fondues sous l'occupation (19401944). In: Gazette des Beaux-Arts, 11e année, Ge pér., t. 83, 1974, S. 129-148, hier 135 ff. 


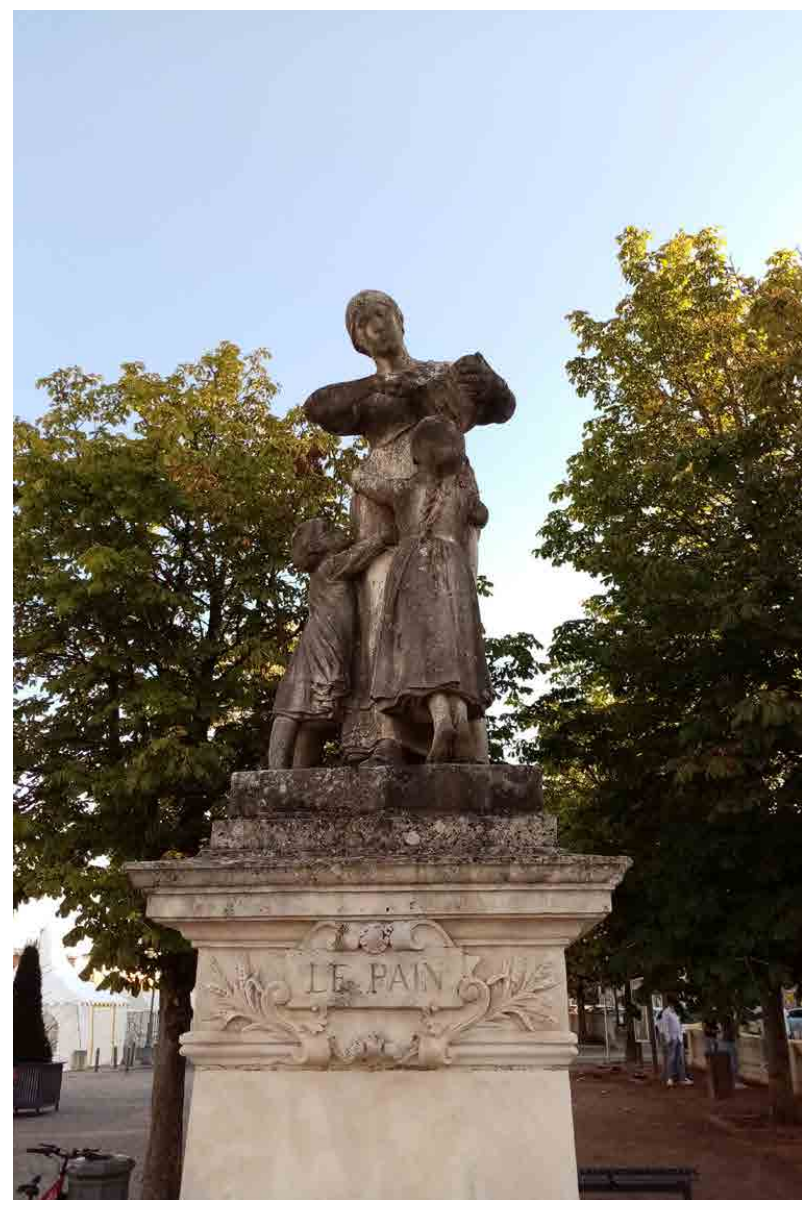

Abb. 23: Albert-Lefeuvre, Louis, Das Brot, 1882 (Gips), 1886 (Marmor), (1887 Einweihung des Denkmals), Parthenay, Place du Drapeau. Foto: Wikimedia Commons, Jalbatros.

Pétain die Einschmelzung der Denkmalsbronzen zum Zweck der Anfertigung von industriellen und landwirtschaftlichen Gerätschaften an. Der Kommission, die über die wegen öffentlichen bzw. historischen Interesses zu bewahrenden Objekte zu befinden hatte, wurde auferlegt, so streng wie irgend möglich zu sein und von allen vom Gefühl diktierten Rücksichtnahmen abzusehen. ${ }^{76}$

Der Widerstand gegen diese Zerstörungsaktion war bescheiden, und der Aufschrei der Empörung nach der Befreiung von Paris und dem Ende der von Marschall Pétain geführten Regierung blieb ganz

\footnotetext{
${ }^{76}$ Ibidem, S. 129 f. Dazu v. a. auch: MICHALSKI, S.: Public Monuments. Art in Political Bondage 1870-1997. London 1998, S. 49 f.
}

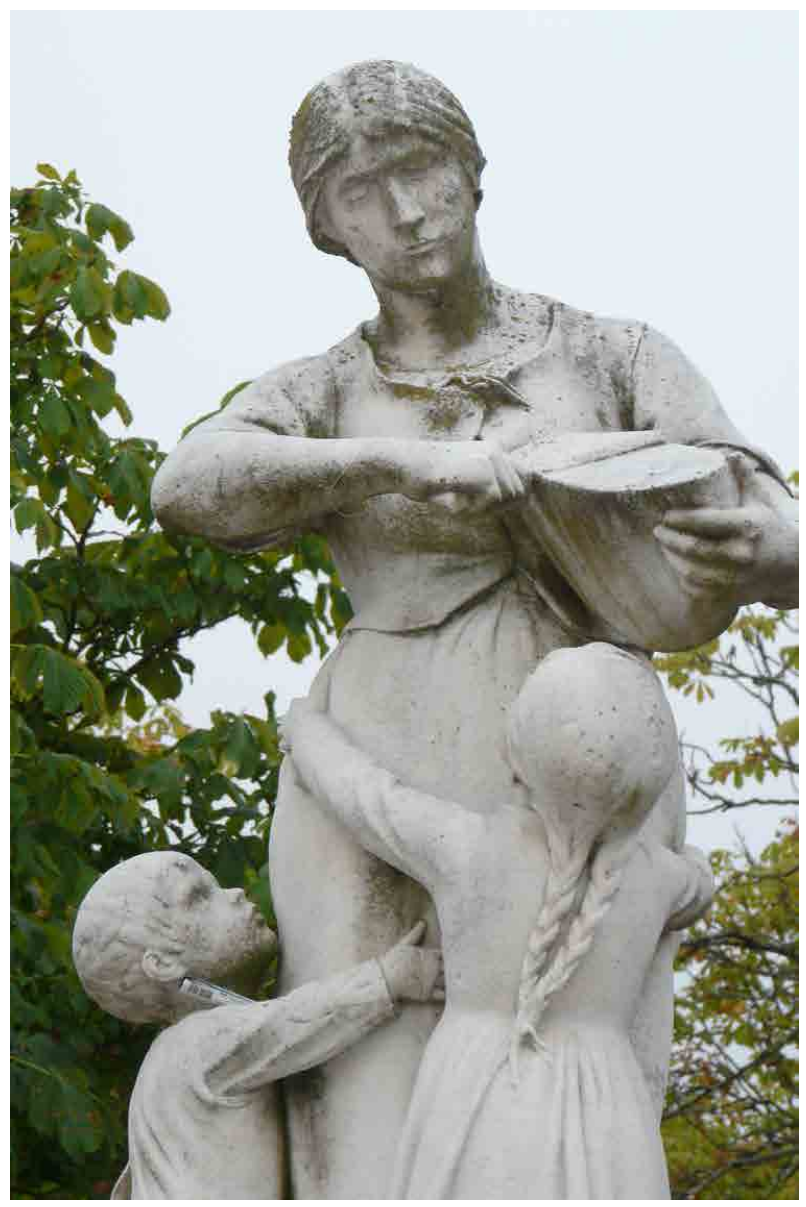

Abb. 24: Albert-Lefeuvre, Louis, Das Brot, 1882 (Gips), 1886 (Marmor), (1887 Einweihung des Denkmals), Parthenay, Place du Drapeau (Detail). Foto: https:// wmw.pinterest.co.uk/pin/303359724877438150/.

aus. ${ }^{77}$ Die Wortführer der öffentlichen Meinung, die Politiker, die Journalisten, die Intellektuellen, die Kunsthistoriker beanspruchten in Sachen Kunst guten Geschmack, und diesem Geschmack wurde die ,andere Moderne' nicht mehr gerecht. Die sogenannten einfachen Bürger, die sich auch über die Denkmäler im öffentlichen Raum mit ihrem Quartier identifiziert hatten, werden vielleicht anders gedacht haben; sie wurden nicht gefragt.

Brot zum Thema einer Statue im Rahmen der Denkmalspolitik der „Dritten Republik“ zu machen, wie Jules Coutan es tat, war außergewöhnlich, aber

\footnotetext{
77 AGULHON, M.: La „Statuomanie“ et l'histoire. In: Ethnologie
} française, nouv. série, t. 8, 1978, S. 145-172, hier S. 146. 
nicht einzigartig. In der selben Salonausstellung des Jahres 1882 gab es eine weitere lebensgroße Statue, die dieses Grundnahrungsmittel monumentalisierte. Louis Albert-Lefeuvre stellte das Gipsmodell einer Mutter aus, die ihren beiden Kindern, die sich hungrig an sie drängen, von einem Brotlaib Scheiben abschneidet. Gleich Coutans Bildwerk kam „Le Pain“ (Das Brot) Albert-Lefeuvres auf den Denkmalssockel; seit 1887 steht sie auf der Place du Drapeau in Parthenay. ${ }^{78}$ (Abb. 23, 24)

Albert-Lefeuvre ist vom Fach Kunstgeschichte noch mehr vergessen worden als sein Kollege Coutan, doch französische Schulkinder wurden bis weit in 20. Jh. hinein mit einer Graphik nach diesem Bildwerk in einem verbreiteten Schulbuch konfrontiert. „Le Pain“ verkörperte dort die Mutter schlechthin, diejenige, so der Schulbuchtext, die den Haushalt führt, während der Mann bei der Feldarbeit, in der Werkstatt ist oder in der Fabrik arbeitet, diejenige, die die Kinder erzieht, das Geld der Familie zusammenhält, damit diejenige, die dafür sorgt, dass immer Brot im Haus ist. ${ }^{79}$ In der Absicht, das Bild der guten Mutter pädagogisch zu verallgemeinern, wird der Schulbuchtext der Graphik nach Albert-Lefeuvre nicht ganz gerecht: Ihr Gewand weist die junge Frau als Bäuerin, nicht etwa als Fabrikarbeitersgattin aus. Darin unterscheiden sich die beiden Monumentalisierungen des Brotes. Albert-Lefeuvres Denkmalsstatue ist nahe bei den würdevollen Bäuerinnen Jean-François Millets, Coutan hob eine Form der großstädtischen Distribution des Brotes, ein Bild

${ }^{78}$ Eine zweites Exemplar (Bronze) befand sich vor dem Rathaus von Cahors.

${ }^{79}$ BIGOT, CH.: La Mère. In: Lectures expliqués avec enseignement moral et civique. Cours élémentaire (2e Année) et Cours moyen (1ere Année). Eds.: BOURCEAU, E. - FABRY, R. Paris 1934 (4. Aufl.), S. 49.

${ }^{80}$ Bemerkenswert ist der Stellenwert, der beiden Denkmalsfiguren für die englische Skulptur zugemessen wurde. Für Hamo Thornycrofts „The Mower“, ein in Hinblick auf die Arbeitshematik und die Darstellung zeitgenössischer Kleidung programmatisches Werk der „New Sculpture“, nannte der Verehrer des Bildhauers, Edmund Gosse, Coutans und Lefeuvres „,ideal realism“ als Vorbild. GOSSE, E.: The new Sculpture III. In: The Art Journal, 1894, S. 278-282, hier S. 280. der niedrigschichtigen Arbeit in der Metropole, auf den Sockel. ${ }^{80}$

Die beiden Denkmalsfiguren wurden als moderne Darstellungen der modernen Lebenswelt wahrgenommen. Auch in England. Hamo Thornycroft gehörte zu den führenden Künstlern der „New Sculpture“ in England, und sein „Mäher“ (1884) war eine der ersten heroisierten Darstellungen eines zeitgenössischen Arbeiters. Nur auf wenige Voraussetzungen konnte er sich kunstgeschichtlich berufen. ${ }^{81}$ Thornycroft selbst verwies in seiner Akademievorlesung von 1885 auf die ,subjects of everyday life“ in Werken Coutans, Albert-Lefeuvres und Pechs. Am 15. Mai 1882 hatte Edmund Gosse zusammen mit Thornycroft den Pariser „Salon“ besucht, auf dem Albert-Lefeuvres „Brot“ und Coutans „Brotausträgerin zu sehen waren. ${ }^{82}$ Albert-Lefeuvres Statue pries Thornycroft als „ein ausgezeichnetes Beispiel einer realistischen und doch skulpturalen Wiedergabe einer robusten und hübschen jungen Bäuerin, die Brotlaibe trägt. ${ }^{\text {(83 }}$ Nun schneidet Albert-Lefeuvres Bäuerin Scheiben von einem Brotlaib ab, trägt nicht mehrere, was darauf schließen lässt, das Thornycroft in der Erinnerung die Statuen Coutans und Albert-Lefeuvres übereinanderblendete.

Von den Salonbesprechungen, die auf beide Plastiken eingehen, sei eine zitiert. Zurecht lobe man Coutan und Lefeuvre, dass sie das Thema ,in eine Sprache übersetzt haben, die jedermann verstehen kann“".84 Der Autor der "Gazette des Beaux-Arts“" bekräftigte seinen literarischen Einsatz für das

${ }^{81}$ Getsy nannte den Arbeiter in Dalous ,Triumph der Republik“ (begonnen 1879, als Bronzedenkmal erst 1899 aufgestellt), Achille D'Orsis „Proximus tuus“ (1880) und Vincenzo Velas Relief der „Opfer der Arbeit“. GETSY, D. J. Body Doubles. Sculpture in Britain 1877-1905. New Haven - London 2002, S. 44.

${ }^{82}$ GETSY, D. J.: The problem of realism in Hamo Thornycroft's 1885 Royal Academy Lecture. In: The volume of the Walpole Society, 69, 2007, S. 211-223, hier S. 222 f.

83 „Le Feuvre's statue entitled ,Bread' is an excellent example of a realistic yet sculpturesque rendering of a robust and handsome young peasant woman carrying loaves of bread." Thornycroft. Zit. in: Ibidem, S. 218.

${ }^{84}$ „dans la langue que tout le monde peut comprendre“. PROUST, A.: Le Salon de 1882, 1er article. In: Gazette des Beaux-Arts, I, 1882, S. 533-554, hier S. 534. 
zeitgenössische Kunstwerk: „Man muss also, ich wiederhole es, mit Nachdruck diese Tendenz der Kunst befürworten, etwas Neues herauszubringen und nicht nur neu aufzulegen. ${ }^{\text {"85 }}$ Bemerkenswert an diesem Lob des Zeitgenössischen und Allgemeinverständlichen ist, von wem dieses Lob kommt. Antonin Proust war der Onkel des Romanciers Marcel Proust, und er hatte hohe politische Funktionen inne. Als er in der Gazette des Beaux-Arts seine Kritik des „Salons“ von 1882 publizierte, war seine Amtszeit als erster Kultusminister mit dem Schwerpunkt auf der Zuständigkeit für die Schönen Künste im Kabinett Gambetta kurz vorher zu Ende gegangen. Seine kurze Amtszeit hatte er neben anderem genutzt, um Edouard Manet den Verdienstorden der Ehrenlegion zu verschaffen. ${ }^{86}$

Es war ihm ein persönliches Anliegen. Proust war ein Jugendfreund Manets gewesen und er blieb ihm zeitlebens freundschaftlich verbunden. 1884 nahm er maßgeblichen Anteil an einer Gedächtnisausstellung für den 1883 Verstorbenen. 1897 veröffentlichte er in der Revue Blanche seine „Erinnerungen an Manet“". Es ist die wichtigste Quelle insbesondere für das, was wir über die Jugend des Malers wissen können. ${ }^{87}$ Bei dem Freund und Förderer Manets, des Künstlers, der sich mehr als jeder andere den (von Baudelaire Constantin Guys zugedachten) Namen eines „Malers des modernen Lebens" verdient hatte, überrascht nicht das in der Salonbesprechung von 1882 nachdrücklich gemachte Bekenntnis zum modernen Leben als Thema von Kunst, doch vielleicht überrascht, dass der Freund und Bewunderer Manets ohne weiteres Werke von Albert-Lefeuvre und Coutan einbezog. Es gab also Überschneidungen zwischen den beiden Modernen, zwischen der Moderne, die Antonin Proust in der brotschneidenden Mutter Albert-Lefeuvres und der „Brotausträgerin“ Coutans sah, und der Moderne, für die in der kunstgeschichtlichen Erzählung von dem, was Moderne, was Avantgarde ist, Edouard Manet an oberer Stelle steht. Edouard Manet besetzt die Kreuzung der beiden Modernen.

Schon bei den Impressionisten, denen Manet nur sehr eingeschränkt zugeordnet werden darf, verschiebt sich der Schwerpunkt. Gewiss werden Bahn-

\footnotetext{
${ }^{85}$ „Il faut donc, je le repète, approuver hautement cette tendance de l'art à éditer et à ne plus rééditer." Ibidem, S. 534.
}

höfe gemalt, das Gewimmel auf dem Boulevard, Picknicks. Doch von dem modernen Phänomen der flanierenden oder hektisch eilenden Masse bzw. der Eisenbahn als Inbegriff moderner Technik löst sich vor allem in den Bildern Claude Monets zunehmend eine Autonomie beanspruchende Farbhaut ab. Nicht weit davon entfernt sind dann Monets „Heuhaufen“ und seine Ansichten der Kathedrale von Rouen zu unterschiedlichen Tageszeiten, Gemälde, an denen alles neu, alles modern ist, außer dem Sujet.

Es ist zuzugeben, dass in diesem Beitrag der ,anderen Moderne' der zweiten Hälfte des 19. Jhs. in Frankreich ein verkürztes Bild der zeitgleichen, allgemein als solche akzeptierten Moderne entgegengehalten wird. Das „moderne Leben“ hat gelegentlich auch da - nicht nur bei Manet - seinen Platz. Es mag genügen, wenn ich an die Bordell- und Cabaretbilder Henri de Toulouse-Lautrecs und an Vincent Van Goghs „Nachtcafé in Arles“ erinnere. Doch in der Rezeption wurden gesellschaftlich relevante Themen gerne in die Psyche des Künstlers ausgelagert und in aller Regel gerann das Abenteuer der Moderne zu einem Abenteuer der Form. Die Erfahrung von moderner Kunst im 20. Jh. war nachhaltig geprägt durch eine inhaltsfeindliche Definition, die sich mit besonderem Nachdruck Adornos „Ästhetik“ zu eigen machen wird. Es berührt seltsam, dass die 1960er und 1970er Jahre, deren progressive Vertreter die Veränderung des Systems auf ihre Fahnen geschrieben hatten und grundsätzlich Werke der Kunst auf ihren systemkritischen Stachel hin interpretierten, die Kunst vom Gegenstand ähnlich radikal säuberten wie die zeitgenössischen Farbfeldmaler.

Wird Avantgarde definiert als Verfügbarkeit über die „Kunstmittel“, Verfügbarkeit, die der Kunst überhaupt erst erlaubt, über die systemimmanente Kritik an bestimmten (meist den historisch unmittelbar vorausgegangenen) Kunstrichtungen hinaus sich allgemein als „Selbstkritik der Kunst in der bürgerlichen Gesellschaft" zu positionieren, und ist - wie bei Peter Bürger nachzulesen - diese Position in der „Entwicklung der Kunst in der bürgerlichen Gesellschaft“ an der „Prädominanz der Form in der Kunst" ablesbar, dann sind ikonographische Belege

\footnotetext{
${ }^{86}$ http://de.wikipedia.org/wiki/Antonin_Proust (9. 3. 2019)

${ }^{87}$ PROUST, A.: Edouard Manet. Souvenirs. Paris 1913.
} 


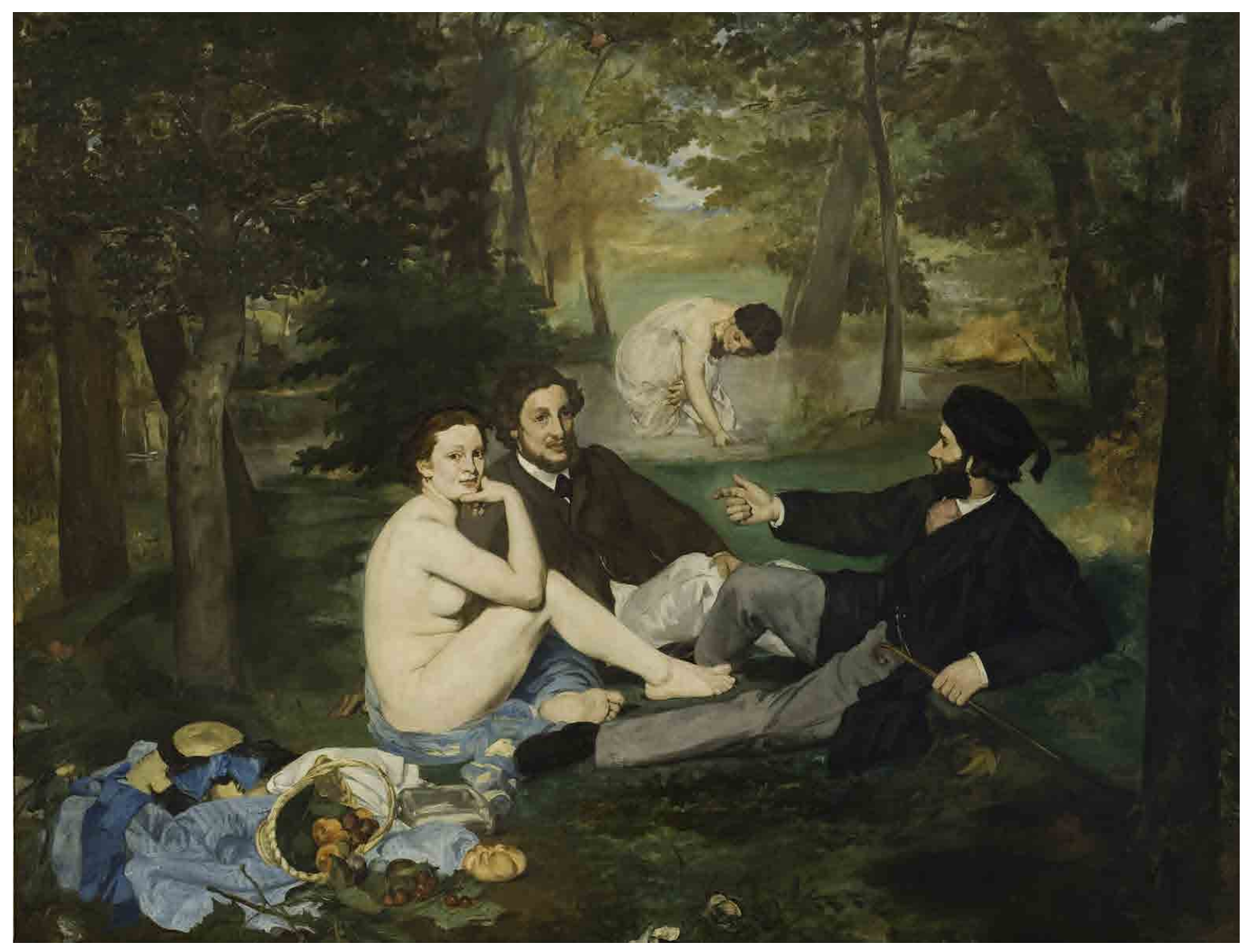

Abb. 25: Manet, Edouard, Das Frühstück im Freien, 1863, Paris, Musée d’Orsay. Foto: Wikimedia commons, twELHYoc3ID_VA at Google Cultural Institute.

für Modernität in der Kunst obsolet geworden: „Die inhaltliche Seite des Kunstwerks, seine ,Aussage', tritt immer weiter zurück gegenüber der formalen Seite, die als das im engeren Sinne Ästhetische sich herausdifferenziert. "88 Absehen vom Konkreten, d. h. Abstraktion, ,garantiert" ,allererst den Freiheitsspielraum (...) innerhalb dessen Alternativen zum Bestehenden denkbar werden. " ${ }^{89}$ Adorno formulierte es knapper: „(D)urch kein Besonderes als Inhalt suspendiert das Kunstwerk die empirische Realität als abstrakten und universalen Funktionszu-

\footnotetext{
${ }^{88}$ BÜRGER, P.: Theorie der Avantgarde. Frankfurt 1974, S. 25.

${ }^{89}$ Ibidem, S. 66 f., 73
}

sammenhang. ${ }^{{ }^{c 90}}$ Es lässt sich auf eine einfache Formel herunterbrechen: Modernität / Avantgarde hat für Adorno und Bürger nichts mit dem Inhalt eines Kunstwerks zu tun, denn wenn man die schlechte Wirklichkeit zeigt, wie sie ist, dann stimmt man ihr eben doch irgendwie zu. Modernität / Avantgarde ist insofern allein eine Frage der Form, da nur Form als vom Inhalt abgelöste subersiv sein kann.

Edouard Manet stand, wie angemerkt, an der Kreuzung der beiden Modernen: Er ist im Sinne von Baudelaires programmatischem Text der „Maler des

${ }^{90}$ ADORNO, TH. W.: Ästhetische Theorie (1970). Frankfurt 1974 (4. Aufl.), S. 203. 
modernen Lebens", damit Protagonist der Moderne, die sich über das Thema des zeitgenössischen urbanen Lebens definiert, und er ist gleichzeitig Protagonist der Moderne, die sich über formale Qualitäten definierte. ${ }^{91}$ Edouard Manets „Déjeuner sur l'herbe“" (Abb. 25) zeigt ein Picknick auf dem Land: eine Waldlichtung, dahinter ein Teich oder ein Wasserlauf. Das Picknick in der Umgebung von Paris gehörte zu den Freizeitvergnügungen der Bevölkerung der Metropole, es war Teil des modernen Lebens. Doch - und das unterscheidet Manets Gemälde von Nachfolgewerken wie Claude Monets „Déjeuner sur l'herbe“ oder von Auguste Renoirs „Déjeuners des Canotiers" -, es geht in der Erzählung eines Essens in freier Natur nicht auf. Es verstört und es hat von Anfang an, seit seiner Präsentation 1863 im „Salon des réfusés", verstört.

Gemessen am Grad der öffentlichen Aufmerksamkeit wurde Manets „Picknick“ zur Sensation dieses Refüsiertensalons. ${ }^{92} \mathrm{Zu}$ einer negativen Sensation. Die Presse fällte vernichtende Urteile, und der Kaiser äußerte sein Missfallen über dieses Bild, das seiner Ansicht nach unanständig war. Dass eine nackte Frau großformatig ins Bild kommt, hätte für sich genommen keinen Anstoß erregt. Gerade die offizielle Salonausstellung des Jahres 1863 war eine Fundgrube für (weiblich) Nacktes. Was vor Manets Gemälde als besonders anstößig erachtet wurde, geht aus der folgenden Kritik hervor: ,Irgendeine dahergelaufene Hure, die so nackt als irgend möglich ist, hat sich auf unverschämte Weise breitgemacht zwischen zwei Aufpassern, die so bekleidet wie irgend möglich sind und Kravatten tragen. (...) Letztere sehen aus wie Studenten in den Ferien, die sich eine Unanständigkeit erlauben, um männlich zu wirken“, so der Kritiker Etienne. ${ }^{93}$

\footnotetext{
${ }^{91}$ In diesem Sinne ADORNO, TH. W.: Im Jeu de Paume gekritzelt (1958). In: Idem: Ohne Leitbild. Parva Aesthetica. Frankfurt 1970 (4. Aufl.), S. 42-47, hier S. 45.
}

${ }^{92}$ Das folgende wiederholt oder paraphrasiert Passagen aus KÖRNER 1996 (wie Anm. 59), S. 65 f., 70 f.

93 „Une bréda quelconque, aussi nue que possible, se prélasse effrontément entre deux gardiens aussi habillés et cravatés (...) ces deux personnages ont l'air des collégiens en vacances, commettant une énormité pour faire les hommes“. Zit. n.
An die Ausgangssituation oder an das entspannte Nachher einer Orgie dachten einige Manet-Forscher, und Manet gab dieser Interpretation insofern Nahrung, als er das 1863 zur Salonausstellung unter dem Titel „Le Bain“ eingereichte Gemälde, das er dann in einer Ausstellung seiner Werke parallel zur Weltausstellung von 1867 „Le déjeuner sur l'herbe“ nannte, 1871 im Kontext der Aufstellung eines Inventars der in seinem Atelier befindlichen Werke wieder anders, jetzt als „La Partie carrée“ betitelte. ${ }^{94}$ „Partie carrée" meint das erotische und / oder sexuelle $\mathrm{Zu}$ sammensein von vier Personen, meist zwei Paaren, wobei Partnerwechsel mit im Spiel der Andeutungen sein kann. ${ }^{95}$ Doch Hinweise auf beginnende oder gewesene sexuelle Aktionen des Bildpersonals fehlen. ${ }^{96}$ Verstörend ist vielmehr die weitgehende Nicht- Bezugnahme der Personen. Der Dandy mit der extravaganten Kopfbedeckung streckt die Hand in Richtung der Aktfigur, Victorine Meurent, Manets bevorzugtem Modell in diesen Jahren, aus, was signalisiert, daß ein Gespräch im Gange ist. Doch der Zeigefinger geht an der Nackten vorbei, das Signal wird auch nicht erwidert. Ferdinand Leenhoff, der Schwager Manets, den man mit der mittleren Figur identifiziert hat, blickt ins Leere, während Victorine Meurent ihr Augenmerk dem Bildbetrachter widmet. Allein die Handgeste versucht einen Zusammenhang herzustellen. Da dieser Appell aber im Wortsinne daneben geht und nicht aufgenommen wird, macht die ins Leere stoßende Geste die Vereinzelung und Beziehungslosigkeit der Figuren noch auffälliger, als sie schon ist. Die Dreiergruppe der Sitzenden isoliert sich ihrerseits im Bildkontext. Innerhalb der Landschaft wiederum isoliert sich die im Bach watende Frau - vermutlich eine Darstellung von Manets Gattin - durch ihre unmaßstäbliche Größe. ${ }^{97}$

Manet 1832-1883, Katalog der Ausstellung, Paris, Grand Palais 1983, Paris 1983, S. 166.

94 ANDERSON 2005 (wie Anm. 54), S. 67 f.

${ }^{95}$ Ibidem, S. 70 f.

${ }^{96}$ Vgl. ibidem, S. 73.

${ }^{97}$ HOWARD, S.: Early Manet and Artful Errors: Foundations of Anti-Illusion in Modern Painting. In: Art Journal XXXVI, 1, 1977, S. 14-21, hier S. 16. 


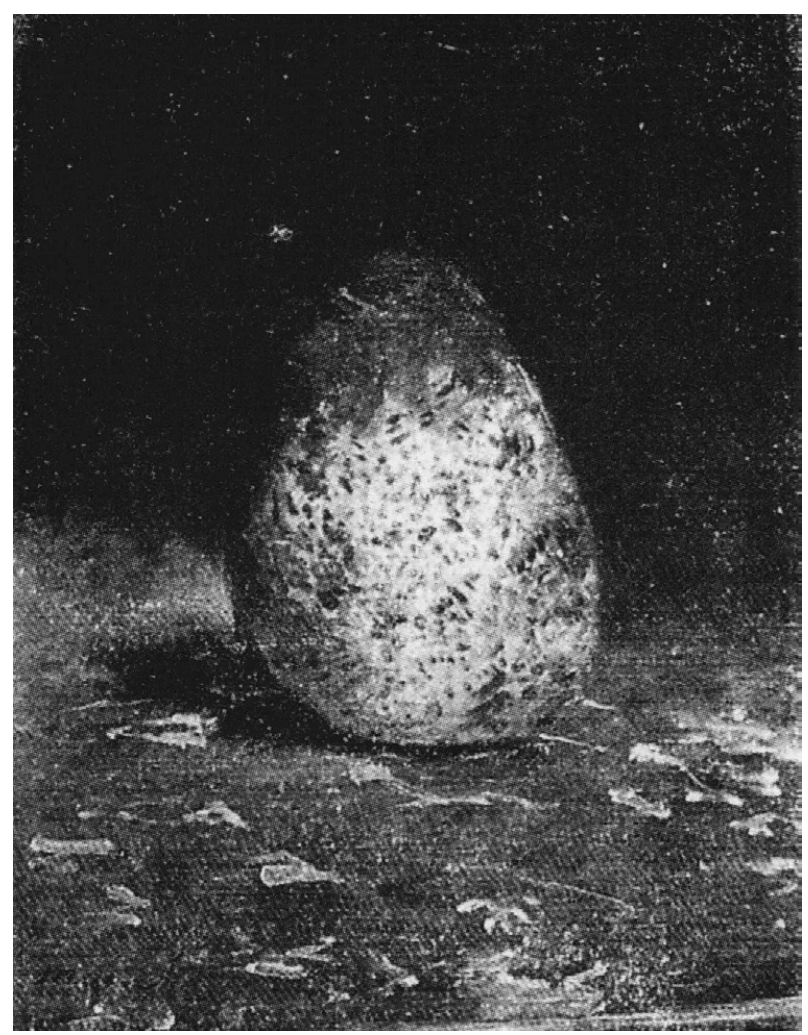

Abb. 26: Manet, Edouard, Birne, 1880, Privatsammlung. Foto: Wikimedia Commons.

Aus dieser Zertrümmerung der traditionellen Bilderzählung, die seit dem italienischen 15. Jh. darauf gründet, dass Personen in einem Historienbild durch Handlung oder Interesse, also durch Gesten, Blicke, Zuwendung miteinander zu verknüpfen sind, resultiert die Isolation der Figuren, und diese Isolation vornehmlich der Aktfigur ist das im eigentlichen Sinne Anstößige. Nichts, nicht einmal eine künftige oder gewesene Orgie, legitimiert diesen nackten Körper. Im traditionellen ästhetischen Sinn funktionslos geworden, wird er, wenn ich vielleicht nicht ganz passend auf die Terminologie von Heideggers „Sein und Zeit" zurückgreifen darf, auffällig und aufsässig. Auffällig und aufsässig wird der nackte

\footnotetext{
${ }^{98}$ AHRENS, B.: Die Déjeuner-Malerei von Edouard Manet, Claude Monet und Pierre-Auguste Renoir. Untersuchung zur Darstellung von Mablzeiten in der Zeit des französischen Impressionismus. Hamburg 2008, S. 84 f.
}

Frauenkörper, doch auch die sonstigen Figuren und Dinge emanzipieren sich als isolierte, entkontextualisierte in beunruhigender Weise. Und das gilt auch für die im Bild versammelten Lebensmittel, für die Früchte, für das Brot, für die Flasche im und neben dem Korb. Auch sie sind funktionslos geworden. Beatrix Ahrens, die in ihrer Dissertation das „Déjeuner"-Thema im Kontext behandelte, wies darauf hin, dass nicht nur niemand bei diesem „Déjeuner“ isst, sondern dass auch niemand essen kann - zum Picknick gehört ein auf das Gras gebreitetes Tuch, Besteck ist auch keines sichtbar, und die gemalten Früchte reifen nicht zur selben Jahreszeit. ${ }^{98}$

So wie bei dem isolierten nackten Körper der Victorine Meurent die Nacktheit keine Referenz mehr hat, bei sich bleibt, derart auffällig und aufsässig wird, so drängt sich in den Lebensmitteln das vor, was sie jetzt vorzüglich sind, nämlich Gegenstände einer wunderbaren Malerei, die die Oberfläche zum „Fest für die Augen“" macht. ${ }^{99}$ Bevor sich dieses Stillleben, und das sind die Lebensmittel gemeinsam mit Korb und mit den ausgezogenen Kleidern zunächst, sich gegenständlich als Strohut, Kleid, Picknickkorb, Früchte, Flasche und Gebäck ausdifferenziert, ist es eine exquisite Kombination von Gelb-, Ocker-, Rotund Grüntönen, getragen von der Dominante des hellstrahlenden Blau. Man versteht von daher Manets Vorliebe für Stilleben, dem Thema, das Malerei auf die peinture, die Kunst der Oberfläche verpflichtet.

Und man versteht, was Edgar Degas, an dem Malerkollegen Manet, mit dem er wiederholt Konflikte austrug, bewunderte: Als sich Degas die Gelegenheit bot, einen ,Jupiter“ von der Hand Ingres“ in seinen Besitz zu bringen, ersparte er keinem seiner Freunde die Besichtigung des Prunkstücks. Auch der irische Dandy und Literat George Moore wurde von Degas vor den antiken Gott geführt. Aufgefordert, seiner Bewunderung Ausdruck zu geben, zögerte Moore, denn neben dem ,Jupiter“ hing unscheinbar ein nur $22 \times 16 \mathrm{~cm}$ großes Bildchen, das nichts anderes als eine wenig ansehnliche Birne darstellte. (Abb. 26) George Moore erinnerte sich, das kleine Stillleben früher in Manets Atelier gesehen zu haben, wo es

\footnotetext{
${ }^{99}$ Ein Wort Eugène Delacroix'.
} 
rahmenlos an die Atelierwand genagelt war. Aus dem Besitz Pertuisets war Manets „Birne“ dann in die Sammlung Degas“ übergegangen. „Im Grunde gefällt mir die Birne besser als der Jupiter", wagte Moore einzuwenden. Statt verärgert über diese nicht gerade enthusiastische Würdigung seiner Neuerwerbung zu sein, stimmte Degas zu: „Ich habe sie dahin gehängt, weil eine Birne, die so gemalt ist, jeden Gott umwirft.“100

Dieser Anekdote läßt sich das Diktum Max Liebermanns anschließen, eine gut gemalte Rübe sei ebenso gut, wie eine gut gemalte Madonna. Max Liebermann war aus dem Autonomieanspruch der zunehmend selbstreferentiell werdenden bildnerischen Mittel noch nicht zum Schluss gekommen, dass eine gut gemalte Rübe dann auch besser sei als als eine schlechter gemalte Madonna. ${ }^{101}$ Diese von Liebermann verweigerte Konsequenz hatte vorher bereits Lantier gezogen, der (Manet und Cézanne nachgebildete) Maler, den Émile Zola in seinem

100 Zit. n. JEDLICKA, G.: Edouard Manet. Zürich 1941, S. 202. Das betreffende Ingres-Gemälde ist vermutlich identisch mit einer Studie mit dem Profilkopf Jupiters, die aus der Sammlung Degas stammt und 2003 bei Sotheby's versteigert wurde. Vgl. http://www.sothebys.com/en/auctions/ecatalogue/2003/19th-century-european-art-including-the-great-19th-century-ateliers-ingres-to-bouguereau-n07930/ lot.47.html (18. 11. 2019)

101 BETH, K.: Stilleben des 19. Jahrbunderts. Studien zur französischen und deutschen Stillebenmalerei. Tübingen 1979, S. 145, KÖNIG, E. - KÜSTER, B. - SCHÖN, CH. - VÖHRINGER, CH.: Hauptthemen in den Quellentexten. In: Stilleben (= Geschichte der klassischen Bildgattungen in Quellentexten und Kommentaren, Bd. 5). Eds.: KÖNIG, E. - SCHÖNE, Ch. Berlin 1996, S. 107-255, hier S. 201 f. Das folgende wiederholt eine Passage aus KÖRNER, H.: Eine Runkelrübe als Tischdekoration. In: Tafel-Dekorationen. Speisegestaltung und Repräsentation. Bulletin Esskulturen. 2. Jg. 2020, Mappe V, Faszikel 9, Koblenz 2020, S. 1-7, hier S. 7.

102 Ibidem, S. 140 f.; KÖNIG - KÜSTER - SCHÖN VÖHRINGER 1996 (wie Anm. 101), S. 200 f.

103 Zumindest hier im Anmerkungsapparat sei ein knapper Ausblick über die kunst- und literaturgeschichtlichen Folgen der „Brotaussträgerin“ angefügt:

Eine Brotausträgerin ist zur Heldin eines der meistgelesenen Romane des französischen 19. Jhs. geworden. Beginnend mit der Ausgabe vom 15. Juni 1884 publizierte Xavier de Montépin in „Le Petit Journal“ den Fortsetzungsroman „La Porteuse
Künstlerroman „L'Oeuvre“ (1886) als beispielhaften Vertreter der Avantgarde und als ebenso beispielhaft gescheiterten Künstler beschrieb. Lantier polemisierte gegen die offizielle Malerei auf der Pariser Salonausstellung, indem er ihr ,Bauchkunst' entgegenhielt: „einen Karottenbund“, und prophezeite, dass der Tag kommen werde, an dem eine einzelne Mohrrübe eine Revolution auslösen werde. ${ }^{102}$

Äpfel, Birnen, Rüben sind wichtig, insofern sie für sich nicht wichtig sind, sondern Vorwände für peinture, für Form. Allgemein: für Kunst, die sich auf sich selbst bezieht. Damit war der Weg für die künstlerische Avantgarde des späten 19. und 20. Jhs. vorgezeichnet, die im ästhetiktheoretischen Diskurs und in der ökonomischen Realität sich als die erfolgreiche herausgestellt hat. Das Oeuvre Edouard Manets hatte den Parallelweg noch offen gelassen, den Weg, auf dem man Objekten der, anderen Moderne' wie den Brunnen des Richard Wallace und der „Brotausträgerin“ des Jules Coutan begegnet. ${ }^{103}$

de Pain“. (Zum Roman, zum Bühnenstück und deren Rezeption in Film und Fernsehen: THOUARD, S.: Mélodrame et imaginaires. Les tribulations d'une héroine populaire: la porteuse de pain. In: Les Archives de la Mise en Scène: spectacles populaires et culture médiatique (1870-1950) (= Arts du spectacle, série: Images et Sons), 2016. Eds.: ALEXANDRE-BERGUES, P. - LALIBERTÉ, M. S. 61-73. Jeanne Fortier, eine junge Witwe, Mutter zweier Kinder, die als Concierge in einer Fabrik in Albertville arbeitet, wird von dem in derselben Fabrik tätigen Vorarbeiter Jacques Garaud bedrängt. Als sie ihn zurückweist, ermordet er den Fabrikbesitzer, eignet sich dessen Erfindung an, setzt die Fabrik in Flammen und sorgt dafür, dass Jeanne Fortier als Schuldige verdächtigt und zu lebenslanger Haft verurteilt wird. Als sie nach Jahren geistiger Umnachtung wieder zur Besinnung kommt, gelingt ihr die Flucht. Unter falschem Namen nimmt sie die Stelle einer Brotausträgerin an, findet ihre Kinder wieder, und es gelingt ihr, den in den USA schwerreich gewordenen Jacques Garaud, der inzwischen ebenfalls unter falschem Namen nach Frankreich zurückgekehrt ist, als den wahren Mörder und Brandstifter zu überführen. Der Erfolg des Romans war derart, dass Montépin gemeinsam mit Jules Dornay 1889 eine Theaterversion auf die Bühne des "Théâtre de l'Ambigu“ brachte. Zahlreiche Filmfassungen und eine Fernsehserie schlossen im 20. Jh. daran an. Eine Taschenbuchausgabe von 1973 trägt auf dem Cover eine Abbildung von Coutans „Porteuse de Pain“. Der Bezug von Bild und Text ist lose. Gemeinsam ist allerdings beiden „Brotausträgerinnen“, der des Literaten und der ehemals bronzenen, dass sie jeweils heroisiert werden, Jeanne Fortier als Heldin eines Melodramas, Coutans Arbeiterin durch den Denkmalssockel. 


\title{
Another Modernity in the Paris of the Third Republic. The "Fontaines Wallace" and Jules Coutan's "Porteuse de pain" as Avant-Garde Art
}

\author{
Résumé
}

The Wallace Collection, London, one of the most important museums of French art of the 18th century, is based on the art collection that Richard, the fourth Marquess of Hertford, and his illegitimate son Richard Wallace had assembled in France. Richard Wallace lived in Paris when France was at war with Prussia (1870/71), he suffered with the Parisians through the months-long siege of the city, and he experienced Paris in the times of the Civil War and the bloody suppression of the Commune uprising. During these difficult times for the French metropolis, Richard Wallace donated large sums of money to support the suffering Parisian population. The Francophile Englishman also proved to be a generous philanthropist in the post-war years. The so-called "Wallace Fountains", which still dominate the cityscape of Paris today go back to his foundation (and his artistic design). The art historical narrative of the avant-gardes of the 19th and 20th centuries completely excluded these objects. The article shows that, in contrast, the eclectic "Fontaines Wallace" even correspond precisely to the original artistic avant-garde concept as it was formed in Saint-Simon's succession.

Ein Seitenblick auch noch auf die weitere Geschichte des von Jules Coutan in die hochschichtige bildende Kunst eingeführte Thema der Brotaussträgerin: Es war der letzte große Auftrag für eine Raumausstattung im Pariser Hôtel de Ville. Adolphe Willette führte ihn 1905 aus, eine schillernde Figur, Maler der Bohème auf dem Montmartre und insbesondere des Pierrots als Verkörperung des Künstlers, fruchtbarer Illustrator und eben auch: einziger „Candidat antisémite“ bei den Wahlen am 22. September 1889. Willette malte im Hôtel de Ville einen Raum mit einem raumfüllenden Wandgemälde aus, dessen Thema das Leben auf der Pariser Straße ist. Wir sehen auf den Wänden dieses Raumes das, was zum Klischee des Pariser Straßenlebens passt: die Straßenjungen,
In another respect, belonging to the "other modernity" of the 19th century is the "Porteuse de pain" of Jules Coutans, which was raised onto the monument plinth in the Square Tour Saint-Jacques in Paris in 1886. It celebrates a representative of low-class work in the metropolis. In the usual art historical narrative, a work like this also tends to represent the antithesis of the artistic avant-garde that was forming in the second half of the 19th century. It is the iconography that makes the "Porteuse de pain" a modern work of art, at least if one takes Charles Baudelaire's text "Le peintre de la vie moderne" as the basis for the definition of modernity. The attribution of this statue to modernity, to the artistic avant-garde, would in any case have been more accurate for Baudelaire than the works dominating "classical modernity", whose modernity Peter Bürger, in the sense of Adorno, defines by the "predominance of form in art", the receding of the content "in relation to the formal side, which differentiates itself as the aesthetic in the narrower sense". (Bürger)

die fröhlichen Besucher der Straßencafés, die dazugehörigen Kellner, Straßenhändler und die anderen typischen Vertreter typischer Berufe, denen man in der Menge begegnen mag, darunter - prominent - eine Brotaussträgerin. Unübersehbar übersetzte Willette Coutans Skulptur in sein Wandgemälde. Und noch jemand ist zu nennen, wenn man über die Ikonographie der Brotausträgerin sprechen will, jemand, über dessen Zugehörigkeit zur Avantgarde niemand streiten wird: Während seines Aufenthaltes im Sommer 1906 im spanischen Gosol, der Aufenthalt, wärend dessen Picasso sich den Weg von seiner „Rosa Periode“ zu den „Demoiselles d'Avignon“ hin ebnete, malte er die „Brotausträgerin von Gosol““. 